\title{
The Impact of CSR on the Performance of a Dual-Channel Closed-Loop Supply Chain under Two Carbon Regulatory Policies
}

Fuan Zhang and $\mathrm{Na} \mathrm{Li}^{*}$ (D)

Citation: Zhang, F.; Li, N. The Impact of CSR on the Performance of a Dual-Channel Closed-Loop Supply Chain under Two Carbon Regulatory Policies. Sustainability 2022, 14, 3021. https: / /doi.org/10.3390/su14053021 Academic Editors: Jan Parobek, Andreja Pirc Barčić, Hubert Paluš and Branko Glavonjic

Received: 11 January 2022

Accepted: 1 March 2022

Published: 4 March 2022

Publisher's Note: MDPI stays neutral with regard to jurisdictional claims in published maps and institutional affiliations.

Copyright: (C) 2022 by the authors. Licensee MDPI, Basel, Switzerland. This article is an open access article distributed under the terms and conditions of the Creative Commons Attribution (CC BY) license (https:// creativecommons.org/licenses/by/ $4.0 /)$.
College of Information Engineering (Artificial Intelligence) School, Yangzhou University, Yangzhou 225000, China; fazhang@yzu.edu.cn

* Correspondence: 13225426069@163.com; Tel.: +86-156-5340-6314

\begin{abstract}
Under different carbon regulatory policies, corporate social responsibility (CSR) activities will have different impacts on the environmental benefits of the supply chain and corporate carbon emission reduction decisions. In this study, we examine a dual-channel closed-loop supply chain consisting of a single manufacturer selling re-products generated from waste products and a single retailer selling new products and consider two settings: enforcing a carbon tax policy or enforcing a subsidy policy. Under each setting, we put CSR into account, construct two models for the retailer to implement or not implement CSR activities, and analyze the decisions obtained under optimal solutions. Through numerical simulation and comparative research, we observe that the carbon tax policy applies to the supply chain where CSR activities are implemented, while the subsidy policy applies to the supply chain where CSR activities are not implemented. Reasonable selection of CSR implementation methods with low-cost coefficients by the retailer is conducive to eliminating profit conflicts among supply chain members. The government should fully consider the decision-making thresholds of supply chain members to ensure the maximum effectiveness of the policy.
\end{abstract}

Keywords: carbon regulatory policies parison; environmental benefits; CSR; dual-channel closedloop supply chain

\section{Introduction}

The annual "Emissions Gap Report" of the United Nations Environment Program found that because of the impact of the COVID-19 pandemic, global carbon dioxide emissions declined in 2020; however, it is still moving towards the developing direction that the world's temperature rises will breakthrough $3{ }^{\circ} \mathrm{C}$ at the end of the century. In recent years, a large number of studies and practices have shown that controlling and reducing carbon emissions is the most direct way to solve the current social problems of environmental degradation and climate warming.

With this background, governments strive to achieve low-carbon emission reduction. Existing carbon emission regulatory policies can be divided into two categories: the first category is binding policies, such as carbon quota trading and the collection of carbon taxes. The other is incentive policies, which mainly contain industrial policies, legislative protection, and government subsidies. As an effective binding policy measure that guides enterprises to reduce and control carbon emissions, the carbon tax policy has been practiced in European Union countries and has achieved results [1,2]. Metcalf Gilbert E [3] has defined a carbon tax and collected some empirical evidence on the impact of existing taxes on emission reductions. Chien et al. [4] suppose that a carbon tax combined with green innovation and strict environmental policies can lead to the realization of sustainable development goals. Zhang et al. [5] found that the progressive carbon tax policy can help reduce carbon emissions when online channels are introduced in the supply chain. In recent years, the implementation of the carbon tax policy has failed to benefit the Swedish 
government in terms of energy innovation. In response to this problem, Cheng et al. [6] analyzed the dynamic relationship between carbon tax revenue and energy innovation in a 10-year period from 1990 to 2019 to advise on Swedish policy adjustments. Using a discrete choice experiment, Hammerle et al. [7] investigated and analyzed Australian public attitudes towards carbon taxes and found that providing recycling revenue for low-carbon technologies can improve emissions reductions. It is found by Nong et al. [8] that the economic contraction rate of developing countries is higher than that of developed countries when carbon tax policies are implemented. Gregmar and Yoder [9] designed an integrated tax-subsidy policy to limit the net income of the government's carbon tax and increase the enthusiasm of enterprises to reduce emissions. Taking the Bohai Bay region of China as an example, the impact of the carbon tax rate and tax cycle share on the economy and carbon emissions has been discussed by Sun et al. [10]. Based on the game theory model, the influence of the government subsidy policy and carbon tax policy on the optimal solution of the remanufacturing model was compared by Li et al. [11].

Among the incentive policies, the government subsidy policy is known for its universality and effectiveness [12]. Xue et al. [13] found that government subsidies are conducive to the renewal of energy-saving products and increasing social welfare. Bian et al. [14] showed that manufacturer subsidies are conducive to improving emission reduction levels and reducing emissions, while consumer subsidies are conducive to improving social welfare. Satoshi and Hiroshi [15] studied the impact of consumer subsidy on carbon reduction and social welfare using the case of solar PV installations in Japan. They found that while subsidies help promote the use of solar panels, it exacerbates social surpluses when the value of carbon reductions does not exceed market prices. It was demonstrated by Zhang et al. [16] that although consumer subsidies are always beneficial to green technology innovation in the automotive industry, under certain conditions, it may lead to a reduction in consumer surplus and corporate profits. Combining the risk aversion characteristics of retailers, Cao et al. [17] compared and analyzed the differences in the impact of non-subsidy strategy, manufacturer subsidy strategy, and consumer subsidy strategy on decision-making. The results show that the green quality level under the manufacturer subsidy strategy is higher than that under the consumer subsidy strategy, but the supply chain can obtain the highest profit under the consumer subsidy strategy. Considering the manufacturer's independent research and development of emission reduction, Sinayi et al. [18] comparatively studied the optimal decision-making of the supply chain with or without government subsidies based on the level of emissions reduction. In a low-carbon economy, a two-stage dynamic game method was used by Ren et al. [19] to study the influence of subsidy strategies on corporate decision-making behavior.

As an important means for companies and stakeholders to achieve social and moral responsibilities, CSR has attracted widespread attention in recent years. As the basic form of corporate ethical capital, CSR can not only bring a good reputation and image to the company but also form an asset similar to "insurance" to ensure the stability of the stakeholder's valuation of the company [20] and, thus, bring it better economic performance [21]. JD.com associates its CSR strategy with the United Nations Sustainable Development Goals and aligns its various social responsibility work with poverty reduction, emission reduction, and equity goals. It makes CSR closely linked with the world's most important future development direction so that the macro sustainable development goals can be implemented and the micro CSR can be enlarged. Another example is the concept system of CSR proposed by the Sinobo Group of "Execution - Responsibility", which has effectively promoted football education for Chinese children and young people. In recent years, scholars from various countries have studied CSR issues in the supply chain mainly from two aspects: one is the effect of CSR behavior on economic benefits; the other is the coordination of the supply chain undertaking CSR.

In previous studies on the impact of CSR behavior on economic benefits, a positive relationship between CSR performance and ad spending was found by Kim et al. [22]. Wagner-Tsukamoto [23] has built comprehensive CSR economics based on Carroll's re- 
search on CSR by combining ethics and economics. Barnett et al. [24] proposed and verified the hypothesis that CSR and financial performance (CFP) have a U-shaped relationship. Chen et al. [25] further affirmed this point of view; they believe that enterprises' CSR activities will cause an immediate loss of profits, but a high level of CSR investment will help enterprises gain product value appreciation and discover new market opportunities. CSR is considered to be an implicit contract between an enterprise and its stakeholders that contains the principle of fairness in CSR-in the process of signing the contract, the stakeholders provide a variety of resources to the enterprise. Therefore, the business activities of the enterprise must respect, recognize, and safeguard the interests of stakeholders in order to eliminate legal barriers [26]. When the company's decisions and behaviors follow the implicit or explicit rules constructed by the stakeholders in the contract, in return, the company will gain the value-added created by them, such as corporate reputation and brand image, and then form the long-term development of the company value guarantee [27]. Sun et al. [28] extended the understanding of CSR to new areas that involve corporate performance risk factors and combined this with another key company feature: marketing capabilities, thereby formulating the interaction between CSR and the company's marketside capabilities to achieve better risk management. Zhang and Ahmad [29] found through research that customers' perceptions of CSR activities can regulate their purchase intentions. In previous research on the coordination of the supply chain undertaking CSR, a single manufacturer-retailer supply chain coordination plan considering inventory prices and CSR was proposed by Raza [30]. Based on a socially responsible manufacturer-retailer closed-loop supply chain (CLSC), the impact of CSR on profits and product recycling was analyzed by Panda et al. [31]. Stranieri et al. [32] proved that CSR could effectively improve the relationship between the upstream and downstream of the food supply chain based on the improvement of vertical coordination and overall environmental policy. The supply chain coordination mechanism that encourages suppliers to reveal CSR cost information has been designed by Liu et al. [33].

The above pieces of literature have conducted in-depth research on the two carbon regulatory policies and CSR behaviors, but when perusing the above literature, we began to ponder that the decision-making of supply chain companies to invest in CSR and carbon emission reduction is conducive to expanding the market share of products, which leads to both types of decisions being affected by government carbon regulation policies. Therefore, based on previous studies, we intend to discuss the following issues through this study:

1. What is the impact of corporate CSR investment behavior on corporate decisionmaking, supply chain performance, and environmental benefits under the carbon tax policy?

2. What is the impact of corporate CSR investment behavior on corporate decisionmaking, supply chain performance, and environmental benefits under the government subsidy policy?

3. What are the differences between the two effects?

4. How can the government and supply chain members make decisions that are more conducive to environmental benefits and supply chain performance when the retailer implements CSR activities?

In summary, this paper compares and discusses the impact of CSR activities on supply chain performance and environmental benefits under two different carbon regulatory policies. The research of this paper provides a scientific theoretical reference for lowcarbon decision-making, optimized operation, and government decision-making of the dual-channel closed-loop supply chain considering CSR.

The follow-up content of this article is as follows. The next section introduces the research gap, theoretical modeling, and model construction premises and provides the model assumptions. Models to explore the impact of CSR under two different policy settings are constructed, solved, and analyzed in Section 3. Section 4 analyzes the model solution results using numerical simulation. Section 5 demonstrates the practical significance of the research combined with specific industry cases. Section 6 summarizes the research findings, 
presents managerial implications, and points out where current research is lacking and where future research is headed.

\section{Problem Description and Assumption}

\subsection{Research Gap}

The pieces of supply chain research literature considering CSR and carbon regulatory policies are listed in Table 1, and the research aspects involved in the literature are summarized.

Table 1. List of research papers on green supply chains considering CSR and carbon regulation policies.

\begin{tabular}{|c|c|c|c|c|c|c|c|}
\hline \multirow[b]{2}{*}{ Article } & \multicolumn{3}{|c|}{ Policy } & \multirow[b]{2}{*}{$\begin{array}{c}\text { Policy } \\
\text { Comparison }\end{array}$} & \multirow[b]{2}{*}{ CSR } & \multirow{2}{*}{$\begin{array}{l}\text { Supply } \\
\text { Chain } \\
\text { Structure }\end{array}$} & \multirow{2}{*}{$\begin{array}{c}\text { Environmentally } \\
\text { Friendly } \\
\text { Production }\end{array}$} \\
\hline & Carbon Tax & $\begin{array}{c}\text { Subsidy } \\
\text { Business } \\
\text { Policy }\end{array}$ & $\begin{array}{c}\text { Consumer } \\
\text { Subsidy } \\
\text { Policy }\end{array}$ & & & & \\
\hline [19] & & $\sqrt{ }$ & $\sqrt{ }$ & $\sqrt{ }$ & & FC & \\
\hline [31] & & & & & $\sqrt{ }$ & CLSC & $\sqrt{ }$ \\
\hline [18] & $\sqrt{ }$ & $\sqrt{ }$ & & $\sqrt{ }$ & & FC & $\sqrt{ }$ \\
\hline [30] & & & & & $\sqrt{ }$ & FC & \\
\hline [13] & & $\sqrt{ }$ & & & $\sqrt{ }$ & FC & \\
\hline [32] & & & & & $\sqrt{ }$ & FC & \\
\hline [33] & & & & & $\sqrt{ }$ & FC & $\sqrt{ }$ \\
\hline [34] & & $\sqrt{ }$ & & & & CLSC & $\sqrt{ }$ \\
\hline [17] & & $\sqrt{ }$ & $\sqrt{ }$ & $\sqrt{ }$ & & FC & $\sqrt{ }$ \\
\hline [14] & & $\sqrt{ }$ & $\sqrt{y}$ & $\sqrt{ }$ & & FC & $\sqrt{ }$ \\
\hline [5] & $\sqrt{ }$ & & & & & DCSC & $\sqrt{ }$ \\
\hline [35] & & $\sqrt{ }$ & $\sqrt{ }$ & $\sqrt{ }$ & & & $\sqrt{ }$ \\
\hline [11] & $\sqrt{ }$ & $\sqrt{ }$ & & $\sqrt{ }$ & & CLSC & $\sqrt{ }$ \\
\hline [36] & $\sqrt{ }$ & & & & & CLSC & $\sqrt{ }$ \\
\hline [37] & & & & & $\sqrt{ }$ & FC & \\
\hline [38] & & $\sqrt{ }$ & & & $\sqrt{ }$ & FC & \\
\hline [39] & & & & & $\sqrt{ }$ & FC & \\
\hline [40] & & & & & $\sqrt{ }$ & FC & \\
\hline [41] & & & & & $\sqrt{ }$ & FC & \\
\hline [42] & & & & & $\sqrt{ }$ & CLSC & $\sqrt{ }$ \\
\hline [43] & & & & & $\sqrt{ }$ & FC & $\sqrt{ }$ \\
\hline [44] & & $\sqrt{ }$ & & $\sqrt{ }$ & $\sqrt{ }$ & FC & \\
\hline [45] & & & & & $\sqrt{ }$ & DCSC & \\
\hline [46] & & & & & $\sqrt{ }$ & CLSC & $\sqrt{ }$ \\
\hline This paper & $\sqrt{ }$ & & $\sqrt{ }$ & $\sqrt{ }$ & $\sqrt{ }$ & DCLSC & $\sqrt{ }$ \\
\hline
\end{tabular}

FC: forward chain, CLSC: closed-loop supply chain, DCSC: dual-channel supply chain, DCLSC: dual-channel closed-loop supply chain.

Table 1 provides a list of literature on government policies, CSR, and green supply chains. It can be seen that some previous studies have only studied supply chain coordination considering CSR, some have only studied supply chain coordination considering government policies, and some studies have considered policy and CSR at the same time but did not involve policy comparison. In addition, the structure of the supply chain is limited to the forward supply chain, closed-loop supply chain, and dual-channel supply chain. Different from the previous literature, the research of this paper will fully involve CSR, a comparative analysis of government policies, the green supply chain, and so forth. Based on the dual-channel closed-loop supply chain, we explore the impact of CSR on supply chain decision-making, performance, and environmental benefits under different carbon regulatory policies. By comparing and analyzing the results under different policies, management conclusions and inspirations can be obtained. 


\subsection{Problem Description}

In a dual-channel closed-loop supply chain composed of a single manufacturer and retailer, both the member enterprises of the supply chain belong to the Stackelberg Game under the complete information. As the channel leader, the manufacturer not only produces new products but also recycles and processes waste products and sells the re-products online, which forms a closed loop of re-product production and sales. The retailer operates offline channels to sell new products that are produced by the manufacturer in the form of physical stores. Due to the influence of consumers' low-carbon preference and government carbon regulatory policies, the manufacturer will adopt low-carbon technology for production, thus increasing the level of carbon emission reduction and expanding the market for products, while the retailer will invest in CSR activities to build a corporate image and increase the sales of new products. The retailer's decision on CSR will inevitably affect the optimal decisions of supply chain members.

In recent years, the new energy vehicle industry has developed rapidly. Upstream manufacturers have used innovative technologies to realize the environmentally friendly development of products and continuously improve their closed loop of online recycling, while downstream retailers are also actively exploring more diversified CSR commitment methods. Therefore, the game and coordination among supply chain enterprises play an increasingly important role. Taking the new energy vehicle industry as the background and combined with the research objectives, the theoretical modeling process of this paper is shown in Figure 1.

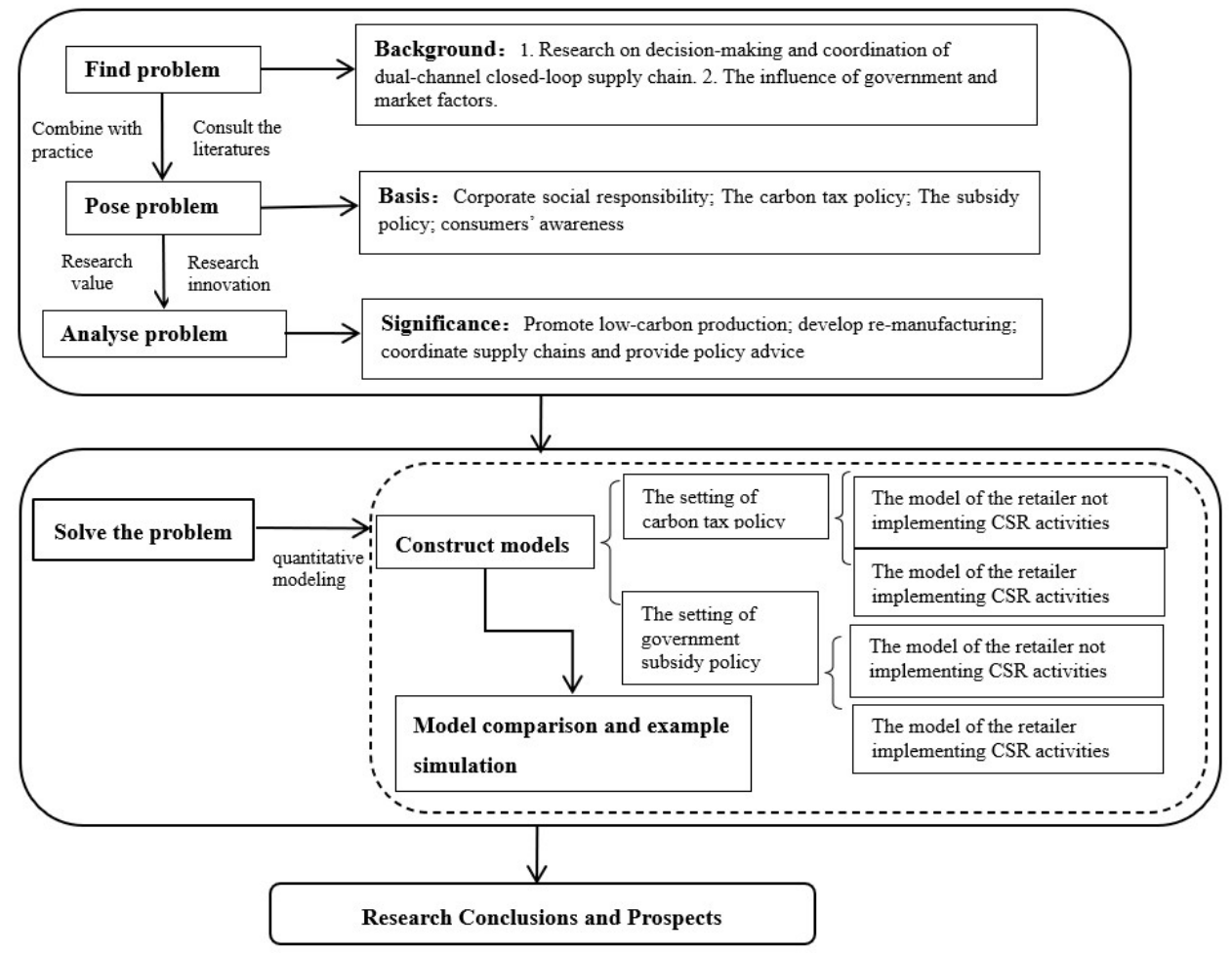

Figure 1. Schematic diagram of the theoretical modeling process.

In the "problem solving" part of Figure 1, we construct a dual-channel closed-loop supply chain decision model under different carbon regulatory policies, as shown in Figure 2, to analyze and compare optimal decisions and explore the impact of CSR activities on supply chain performance and environmental benefits in two settings. 


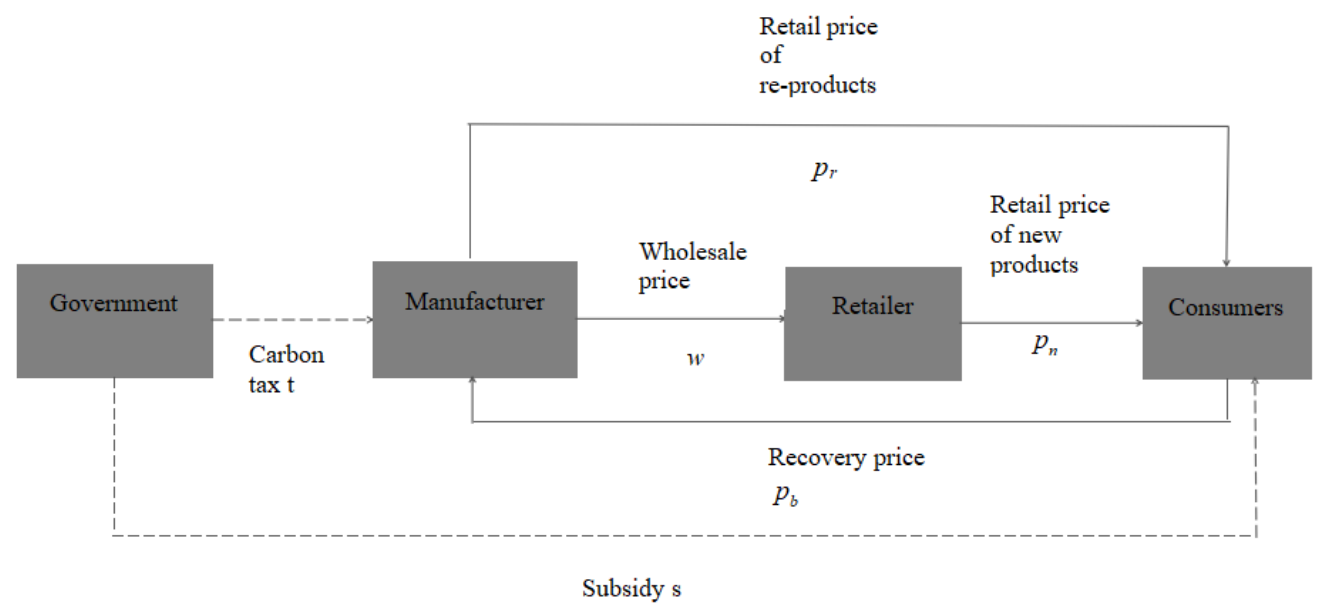

Figure 2. The dual-channel closed-loop supply chain.

\subsection{Model Assumption}

In order to focus on the research key points, the assumptions that do not affect the model derivation are as follows:

Hypothesis 1. To improve the competitiveness of products, the manufacturer uses low-carbon technology for production. The initial carbon emission of per unit new products is $e_{0}$ and the carbon emission of re-products is $\lambda e_{0}, \lambda \in[0,1]$. The larger the value of $\lambda$, the weaker the lowcarbon effect of re-products; on the contrary, the stronger the low-carbon effect of re-products [34]. $C(e)=\frac{1}{2} \mu *\left(e_{0} \varepsilon\right)^{2}$ represents the carbon emission reduction cost function, where $\mu$ is the input cost coefficient of carbon emission reduction, and $\varepsilon$ represents the manufacturer's carbon emission reduction level, $\varepsilon \in[0,1]$. After the manufacturer reduces emissions, the carbon reduction per unit of new product is $e_{0} \varepsilon$, and the carbon reduction per unit of re-product is $\lambda e_{0} \varepsilon$ [47].

Hypothesis 2. The recycling price is determined by the market, and apart from the recycling price, the manufacturer does not consider other costs in the process of recycling wasted products.

Hypothesis 3. $Q$ represents the consumers' maximum willingness to pay; the consumers' willingness to pay for new products is $\theta, 0 \leq \theta \leq Q$. Consumers have doubts about the quality and reliability of re-products due to low awareness of remanufactured technology [48], making them less willing to pay for re-products than new products [49]. Consumers' willingness to pay for re-products is $\alpha \theta, \alpha \in[0,1][50]$.

Hypothesis 4. $v$ represents the CSR investment level of the retailer; the cost function of the CSR investment is $c(v)=\eta v^{2}, \eta$ represents the input cost coefficient of CSR.

Hypothesis 5. To specifically show the impact of CSR activities on the effect of environmental benefits and performance of the supply chain, this paper introduces a difference parameter $\Delta A$ to represent the difference between the optimal decision and performance of Model $N$ and Model $R$, $\Delta A^{i}=A^{i N}-A^{i R}, A=\left\{\varepsilon, E, \pi_{m}, \pi_{r}, p_{n}, p_{r}\right\}, i=\{T, S\}$.

The notations used for the modeling in this paper are presented in Table 2. 
Table 2. Notation summary.

\begin{tabular}{|c|c|}
\hline Notation & Description \\
\hline \multicolumn{2}{|c|}{ Indices and scripts } \\
\hline $\mathrm{m}, \mathrm{r}$ & Represents manufacturer and retailer \\
\hline $\mathrm{T}, \mathrm{S}$ & Setting with carbon tax policy and with subsidy policy \\
\hline $\mathrm{R}, \mathrm{N}$ & Scenario with and without CSR activities that are implemented by retailer \\
\hline & Value of Nash equilibrium \\
\hline \multicolumn{2}{|c|}{ Parameters and variables } \\
\hline$\pi_{0}$ & $\begin{array}{l}\text { Represents profit, } o=\{m, r\} \text {, when } o=m \text {, } \\
\text { represents the profit of the manufacturer; when } o=r \text {, represents the profit of } \\
\text { the retailer. }\end{array}$ \\
\hline$E$ & Environmental benefits of supply chain \\
\hline$c$ & The unit manufacturing cost \\
\hline$\delta$ & Remanufacturing capabilities of the manufacturer, $\delta>$ \\
\hline$w$ & $\begin{array}{l}\text {, the unit remanufacturing } \cos t \text { is } c-\delta[51] \\
\text { The wholesale price of new product (decision variable of the manufacturer) }\end{array}$ \\
\hline$p_{r}$ & The retail price of re-product (decision variable of the manufacturer) \\
\hline$p_{n}$ & The retail price of new product (decision variable of the retailer), $p_{n}>p_{r}$ \\
\hline$p_{b}$ & Price of waste product, $p_{b} \leq \delta[51]$ \\
\hline$\Delta A^{i}$ & $\begin{array}{l}\text { the difference between Model } \mathrm{N} \text { and Model } \mathrm{R} \\
\Delta A^{i}=A^{i N}-A^{i R}, A=\left\{\varepsilon, E, \pi_{m}, \pi_{r}, p_{n}, p_{r}\right\}, i=\{T, S\} .\end{array}$ \\
\hline$e_{0}$ & The initial carbon emissions per unit new product \\
\hline$\lambda$ & $\begin{array}{l}\text { Discount on initial carbon emissions of re-products, } \lambda \in[0,1] \text {. The larger } \lambda \\
\text { means the higher the carbon emission of re-products, and the weaker the } \\
\text { low-carbon effect of re-products. }\end{array}$ \\
\hline$\mu$ & Carbon emission reduction input cost coefficient \\
\hline$\varepsilon$ & $\begin{array}{l}\text { Manufacturer's carbon reduction level, } \varepsilon \in[0,1] \text { (decision variable of the } \\
\text { manufacturer) }\end{array}$ \\
\hline$Q$ & Consumers' maximum willingness to pay \\
\hline$\widetilde{\theta}$ & Consumers' willingness to pay for new products, $0 \leq \theta \leq Q$ \\
\hline$\alpha$ & Discount on consumers' willingness to pay for re-products, $\alpha \in[0,1]$ \\
\hline$\gamma$ & Consumer low-carbon preference \\
\hline$s$ & Subsidies received by consumers for purchasing unit re-products \\
\hline$t$ & The tax rate of carbon tax policy \\
\hline$v$ & The CSR investment level of the retailer \\
\hline$\eta$ & The input cost coefficient of CSR \\
\hline$\beta$ & The sensitivity coefficient of consumers to CSR \\
\hline$U$ & The utility of consumer \\
\hline$\hat{v}_{j}^{i}$ & The threshold of CSR investment level, $i=\{T, S\}, j=\{1,2,3,4\}$ \\
\hline
\end{tabular}

\section{Model Construction and Solution}

In this paper, under the setting of enforcement of the carbon tax policy and the setting of the government subsidy policy, two comparative decision-making models have been constructed respectively: a dual-channel closed-loop supply chain decision-making model without CSR activities (Model N); a dual-channel closed-loop supply chain decision model with CSR activities (Model R).

\subsection{Demand Function Analysis}

The manufacturer produces both new products and re-products, and consumers choose to buy new products offline or buy re-products directly online.

Based on consumer utility theory [52], the utility obtained by consumers buying a unit of new product in the carbon tax policy setting is $U_{n}^{T N}=\theta+\gamma e_{0} \varepsilon-p_{n}$; the utility obtained by consumers buying a unit of re-product is $U_{r}^{T N}=\alpha \theta+\gamma e_{0}(1-\lambda+\lambda \varepsilon)-p_{r}$. When the retailer implements CSR activities, the utility obtained by consumers buying a unit of new product is $U_{n}^{T R}=\theta+\gamma e_{0} \varepsilon-p_{n}+\beta v$; the utility obtained by consumers buying a unit of re-product is $U_{r}^{T R}=\alpha \theta+\gamma e_{0}(1-\lambda+\lambda \varepsilon)-p_{r}$.

In the subsidy policy setting, the utility obtained by consumers buying a unit of new product is $U_{n}^{S N}=\theta+\gamma e_{0} \varepsilon-p_{n}$; the utility obtained by consumers buying a unit of re-product is $U_{r}^{S N}=\alpha \theta+\gamma e_{0}(1-\lambda+\lambda \varepsilon)-p_{r}+s$. When the retailer implements CSR activities, the utility obtained by consumers buying a unit of new product is $U_{n}^{S R}=$ 
$\theta+\gamma e_{0} \varepsilon-p_{n}+\beta v$; the utility obtained by consumers buying a unit of re-product is $U_{r}^{S R}=$ $\alpha \theta+\gamma e_{0}(1-\lambda+\lambda \varepsilon)-p_{r}+s$.

According to the utility function, under the carbon tax policy, when the retailer does not implement CSR activities, the demand function of new products is $q_{n}^{T N}=\int_{p_{n}-\gamma e_{0} \varepsilon}^{Q} d \theta=Q+$ $\gamma e_{0} \varepsilon-p_{n}$ the demand function of re-products is $q_{r}^{T N}=\int_{\frac{p_{r}-\gamma e_{0}(1-\lambda+\lambda \varepsilon)}{\alpha}}^{Q} d \theta=Q-\frac{p_{r}-\gamma e_{0}(1-\lambda+\lambda \varepsilon)}{\alpha}$

When the retailer implements CSR activities, the demand function of new products is $q_{n}^{T R}=\int_{p_{n}-\gamma e_{0} \varepsilon-\beta v}^{Q} d \theta=Q-\left(p_{n}-\gamma e_{0} \varepsilon-\beta v\right)$; the demand function of re-products is $q_{r}^{T R}=\int_{\frac{p_{r}-\gamma e_{0}(1-\lambda+\lambda \varepsilon)}{\alpha}}^{Q} d \theta=Q-\frac{p_{r}-\gamma e_{0}(1-\lambda+\lambda \varepsilon)}{\alpha}$.

Under the subsidy policy, when the retailer does not implement CSR activities, the demand function of new products is $q_{n}^{S N}=\int_{p_{n}-\gamma e_{0} \varepsilon}^{Q} d \theta=Q+\gamma e_{0} \varepsilon-p_{n}$; the demand function of re-products is $q_{r}^{S N}=\int_{\underline{p_{r}-\gamma e_{0}(1-\lambda+\lambda \varepsilon)-s}}^{Q} d \theta=Q-\frac{p_{r}-s-\gamma e_{0}(1-\lambda+\lambda \varepsilon)}{\alpha}$.

When the retailer implements CSR activities, the demand function of the new product is $q_{n}^{S R}=\int_{p_{n}-\gamma e_{0} \varepsilon-\beta v}^{Q} d \theta=Q-\left(p_{n}-\gamma e_{0} \varepsilon-\beta v\right)$; the demand function of the re-product is $q_{r}^{S R}=\int_{\frac{p_{r}-\gamma e_{0}(1-\lambda+\lambda \varepsilon)-s}{\alpha}}^{Q} d \theta=Q-\frac{p_{r}-s-\gamma e_{0}(1-\lambda+\lambda \varepsilon)}{\alpha}$.

\subsection{Carbon Tax Policy Setting (Setting T)}

3.2.1. Retailer Does Not Implement CSR Activities (Model TN)

The profit function of the manufacturer:

$$
\underset{p_{r}, \varepsilon}{\operatorname{AXX}} \pi_{m}^{T N}=q_{n}^{T N}\left[w-c-e_{0}(1-\varepsilon) t\right]+q_{r}^{T N}\left[p_{r}-c+\delta-p_{b}-\lambda e_{0}(1-\varepsilon) t\right]-\frac{1}{2} \mu\left(e_{0} \varepsilon\right)^{2}
$$

The profit function of the retailer:

$$
\underset{p_{n}}{\operatorname{MAX} \pi_{r}^{T N}}=q_{n}^{T N}\left[p_{n}-w\right]
$$

The function of environmental benefits:

$$
E^{T N}=q_{n}^{T N} e_{0} \varepsilon+q_{r}^{T N} e_{0}(1-\lambda+\lambda \varepsilon)
$$

\subsubsection{Retailer Implements CSR Activities (Model TR)}

The profit function of the manufacturer:

$$
\underset{p_{r}, \varepsilon}{M A X} \pi_{m}^{T R}=q_{n}^{T R}\left[w-c-e_{0}(1-\varepsilon) t\right]+q_{r}^{T R}\left[p_{r}-c+\delta-p_{b}-\lambda e_{0}(1-\varepsilon) t\right]-\frac{1}{2} \mu\left(e_{0} \varepsilon\right)^{2}
$$

The profit function of the retailer:

$$
\underset{p_{n}, v}{\operatorname{MAX}} \pi_{r}^{T R}=q_{n}^{T R}\left[p_{n}-w\right]-\eta v^{2}
$$

The function of environmental benefits:

$$
E^{T R}=q_{n}^{T R} e_{0} \varepsilon+q_{r}^{T R} e_{0}(1-\lambda+\lambda \varepsilon)
$$

Theorem 1. When $\left\{\begin{array}{c}2\left[\alpha(\mu-\gamma t)-2 \gamma \lambda^{2} t\right]>\lambda^{2}(\gamma-t)^{2} \\ \beta^{2}<4 \eta \\ \frac{8 \alpha \gamma \eta t}{\beta^{2}-4 \eta}+2 \alpha \mu>\lambda^{2}(\gamma+t)^{2}\end{array}\right.$, the models in the Setting Thave the optimal decision, as shown in Table 3. The detailed derivation is in Appendix A. 
Table 3. Equilibrium results and profits in different decision-making models of Setting T.

\begin{tabular}{|c|c|c|}
\hline & Model TN & Model TR \\
\hline$p_{n}^{*}$ & $\frac{\gamma e_{0} \varepsilon^{T N *}+Q+w}{2}$ & $-\frac{2 e_{0} \gamma \eta \varepsilon^{T R *}+2 \eta Q-\left(\beta^{2}-2 \eta\right) w}{\beta^{2}-4 \eta}$ \\
\hline$v^{*}$ & - & $\frac{\beta\left(w-e_{0} \varepsilon^{T R *} \gamma-Q\right)}{\beta^{2}-4 \eta}$ \\
\hline$p_{r}^{*}$ & $\underline{p_{b}+c-\delta+(1-\lambda) e_{0} \gamma+\alpha Q+e_{0} \lambda\left[t+\varepsilon^{T N *}(\gamma-t)\right]}$ & $p_{b}+c-\delta+(1-\lambda) e_{0} \gamma+\alpha Q+e_{0} \lambda\left[t+\varepsilon^{T R *}(\gamma-t)\right]$ \\
\hline$\pi_{r}^{*}$ & $\frac{\left(\gamma e_{0} \varepsilon^{T N *}+Q-w\right)^{2}}{4}$ & $-{\frac{\eta\left(e_{0} \gamma \varepsilon^{T R *}+Q-w\right)}{\beta^{2}-4 \eta}}^{2}$ \\
\hline$\pi_{m}^{*}$ & $\begin{array}{c}\frac{\left\{p_{b}+c-\delta-(1-\lambda) e_{0} \gamma-\alpha Q+e_{0} \lambda\left[t-\varepsilon^{T N *}(\gamma+t)\right]\right\}^{2}}{4 \alpha} \\
-\frac{\left(e_{0} \varepsilon^{T N *}\right)^{2} \mu+2\left(\gamma e_{0} \varepsilon^{T N *}+Q-w\right)\left[c+e_{0}\left(1-\varepsilon^{T N *}\right) t+w\right]}{2}\end{array}$ & $\begin{array}{c}\frac{\left\{p_{b}+c-\delta+(1-\lambda) e_{0} \gamma+\alpha Q+e_{0} \lambda\left[t+\varepsilon^{T R *}(\gamma-t)\right]\right\}^{2}}{4 \alpha} \\
-\frac{\left(e_{0} \varepsilon^{T R *}\right)^{2} \mu}{2}-\frac{8 \eta\left(e_{0} \varepsilon^{T R *} \gamma+Q-w\right)\left[-c-e_{0}\left(1-\varepsilon^{T R *}\right) t+w\right]}{4\left(\beta^{2}-4 \eta\right)}\end{array}$ \\
\hline$E^{*}$ & $e_{0} \frac{p_{b}+c-\delta+(1-\lambda) e_{0} \gamma+\alpha Q+e_{0} \lambda[t+(\gamma-t)]}{2 \alpha}+\frac{e_{0} \varepsilon^{T N *}\left(e_{0} \varepsilon^{T N *} \gamma+Q-w\right)}{2}$ & $\frac{e_{0}\left[\left(1-\varepsilon^{T R *}\right) \lambda-1\right]\left\{p_{b}+c-\delta+(1-\lambda) e_{0} \gamma+\alpha Q+e_{0} \lambda\left[t+\varepsilon^{T R *}(\gamma-t)\right]\right\}}{-\frac{2 e_{0} \varepsilon^{T R *} \eta\left(e_{0} \varepsilon^{T R *} \gamma+Q-w\right)}{2 \alpha}}$ \\
\hline$\varepsilon^{*}$ & $\begin{array}{c}\frac{\lambda(\gamma+t)\left[p_{b}+c-\delta-e_{0} \gamma+e_{0} \lambda(\gamma+t)\right]}{e_{0}\left[(\gamma+t)^{2} \lambda^{2}+2 \alpha(\gamma t-\mu)\right]} \\
+\frac{\alpha\left[c \gamma-t(Q+\lambda Q-w)-\gamma\left(\lambda Q-e_{0} t+w\right)\right]}{e_{0}\left[(\gamma+t)^{2} \lambda^{2}+2 \alpha(\gamma t-\mu)\right]}\end{array}$ & $\begin{array}{c}\frac{\beta_{b} \lambda\left(\beta^{2}-4 \eta\right)(\gamma+t)+\left(\beta^{2}-4 \eta\right) \lambda(\gamma+t)\left[c-\delta-(1-\lambda) e_{0} \gamma+e_{0} \lambda t\right]}{e_{0}\left\{\left(\beta^{2}-4 \eta\right)\left[(\gamma+t)^{2} \lambda^{2}-2 \alpha \mu\right]-8 \eta \alpha \gamma\right\}} \\
-\frac{\alpha Q \beta^{2} \lambda(\gamma+t)+4 \eta \alpha\left[c \gamma-t(Q+\lambda Q-w)-\gamma\left(\lambda Q-e_{0} t+w\right)\right]}{e_{0}\left\{\left(\beta^{2}-4 \eta\right)\left[(\gamma+t)^{2} \lambda^{2}-2 \alpha \mu\right]-8 \eta \alpha \gamma\right\}}\end{array}$ \\
\hline
\end{tabular}

Proposition 1. $\varepsilon^{T R *}$ increases monotonically with $v ; E^{T R *}$ increases monotonically with $v$.

Proposition 1 manifests that the optimal carbon emission reduction levels under the carbon tax policy will increase with the CSR investment level; the same is true for the environmental benefits of the supply chain. Therefore, in the closed-loop supply chain system where the carbon tax policy has been enforced, the increase in the CSR investment level is conducive to guiding manufacturing companies to raise the level of carbon emission reduction, increase the environmental benefits of the supply chain, and enhance product competitiveness, thereby realizing the benign operation of the green value chain.

Proposition 2. In the carbon tax policy setting, we contrast Model TN with Model TR and obtain: 1. $\quad \varepsilon^{T N *} \leq \varepsilon^{T R *} ; E^{T N *} \leq E^{T R *}$.

2. $\quad p_{n}^{T N *}<p_{n}^{T R *}$; when $\gamma<t, p_{r}^{T N *}>p_{r}^{T R *}$; when $\gamma \geq t$, $p_{r}^{T N *} \leq p_{r}^{T R *}$.

3. $\pi_{m}^{T N *} \leq \pi_{m}^{T R *}$; when $v \geq \hat{v}_{1}^{T}, \pi_{r}^{T N *} \geq \pi_{r}^{T R *}$; when $v<\hat{v}_{1}^{T}, \pi_{r}^{T N *}<\pi_{r}^{T R *}$.

$\hat{v}_{1}^{T}=-2\left[(\gamma+t)^{2} \lambda^{2}+\gamma t \alpha-2 \alpha \mu\right]$

$* \frac{\lambda(\gamma+t)\left[\gamma\left(p_{b}+c-\delta+e_{0} \lambda t\right)-(1-\lambda) e_{0} \gamma^{2}+\lambda(\gamma+t)(Q-w)\right]+\alpha\left\{c \gamma^{2}+2 \mu(w-Q)-\gamma t[w-(1-\lambda) Q]-\gamma^{2}\left(\lambda Q-e_{0} t+w\right)\right\}}{\beta\left[(\gamma+t)^{2} \lambda^{2}+\gamma t \alpha-2 \alpha \mu\right]^{2}-4 \eta\left[(\gamma+t)^{2} \lambda^{2}+2 \gamma t \alpha-2 \alpha \mu\right]^{2}}$

The proof is shown in Appendix B.

Proposition 2 parts 1 and 2 demonstrate that under the carbon tax policy, the implementation of CSR activities increases the manufacturer's investment in low-carbon production to expand the product market, thereby increasing the environmental benefits of the entire supply chain. Meantime, to make up for CSR input costs, the retailer will increase the prices of new products. Auger et al. found through practice that $70 \%$ of consumers have a high recognition of the CSR attributes of products [53]. Hence, the increase in product prices can increase retailers' profits. When the consumer's low-carbon preference is less than the carbon tax rate, CSR activities increase the marginal profit of re-products, so the manufacturer will lower the price of re-products to expand sales of re-products. When the consumer's low-carbon preference is greater than the carbon tax rate, the opposite is true. Based on the above results, the government setting carbon tax rates according to different supply chain market factors will help the manufacturer pay attention to the low-carbon properties of re-products, thereby expanding the scale of remanufacturing and promoting the development of the circular economy. 
Part 3 reveals an interesting outcome, whereby under the carbon tax policy, the retailer's implementation of CSR activities always increases the manufacturer's profits. Meanwhile, when the CSR investment level does not exceed threshold $\hat{v}_{1}^{T}$, the retailer can increase the profit by implementing CSR activities. Threshold $\hat{v}_{1}^{T}$ is positively correlated with the consumers' CSR sensitivity coefficient and with the CSR input cost coefficient negative correlation.

Inference 1. In the government subsidy policy setting, there is an ideal range of CSR investment levels: $\left(0, \hat{v}_{1}^{T}\right]$, which expands with the increase of the carbon tax rate.

From inference 1, we know that under the carbon tax policy, when the CSR investment level of the retailer is within a certain range, the implementation of CSR activities is profitable to both retailer and manufacturer, which achieves the ideal state of the retailer's CSR investment level where the implementation of CSR activities will not harm the interests of any member of the supply chain.

\subsection{Government Subsidy Policy Setting (Setting S)}

3.3.1. Retailer Does Not Implement CSR Activities (Model SN)

$$
\underset{p_{r}, \varepsilon}{M A X} \pi_{m}^{S N}=q_{n}^{S N}[w-c]+q_{r}^{S N}\left[p_{r}-c+\delta-p_{b}\right]-\frac{1}{2} \mu\left(e_{0} \varepsilon\right)^{2}
$$

The profit function of the retailer:

$$
\underset{p_{n}}{M A X} \pi_{r}^{S N}=q_{n}^{S N}\left[p_{n}-w\right]
$$

The function of environmental benefits:

$$
E^{S N}=q_{n}^{S N} e_{0} \varepsilon+q_{r}^{S N} e_{0}(1-\lambda+\lambda \varepsilon)
$$

3.3.2. Retailer Implements CSR Activities (Model SR)

The profit function of the manufacturer:

$$
\underset{p_{r}, \varepsilon}{M A X} \pi_{m}^{S R}=q_{n}^{S R}[w-c]+q_{r}^{S R}\left[p_{r}-c+\delta-p_{b}\right]-\frac{1}{2} \mu\left(e_{0} \varepsilon\right)^{2}
$$

The profit function of the retailer:

$$
\underset{p_{n}, v}{M A X} \pi_{r}^{S R}=q_{n}^{S R}\left[p_{n}-w\right]-\eta v^{2}
$$

The function of environmental benefits:

$$
E^{S R}=q_{n}^{S R} e_{0} \varepsilon+q_{r}^{S R} e_{0}(1-\lambda+\lambda \varepsilon)
$$

Theorem 2. When $\left\{\begin{array}{c}2 \mu \alpha>\gamma^{2} \lambda^{2} \\ \beta^{2}<4 \eta\end{array}\right.$, the models in Setting S have the optimal decision, as shown in Table 4. The detailed derivation is in Appendix A. 
Table 4. Equilibrium results and profits in different decision-making models of Setting S.

\begin{tabular}{|c|c|c|}
\hline & Model SN & Model SR \\
\hline$p_{n}^{*}$ & $\begin{array}{l}\frac{2 p_{b}+(2+\alpha) c+2 Q(2-\alpha)+w(4-\alpha)}{8} \\
-\frac{2 \delta+2 e_{0} \gamma\left(1-2 \varepsilon^{S N *}-\lambda+\varepsilon^{S N *} \lambda\right)+2 s}{8}\end{array}$ & $-\frac{2 e_{0} \varepsilon^{S R *} \gamma \eta+2 \eta Q-\beta^{2} w+2 \eta w}{\beta^{2}-4 \eta}$ \\
\hline$v^{*}$ & $-\frac{8}{2 p_{u}+c+\alpha c-2 \delta+2 \operatorname{en} \gamma(1-\lambda+\varepsilon S N * \lambda)+\alpha(2 O-w)+2 s}$ & $-\frac{\beta\left(e_{0} \varepsilon^{S R *} \gamma+Q-w\right)}{\beta^{2}-4 \eta}$ \\
\hline $\begin{array}{l}p_{r}^{*} \\
\varepsilon^{*}\end{array}$ & $\begin{array}{l}\frac{2 p_{b}+c+\alpha c-2 \delta+2 e_{0} \gamma\left(1-\lambda+\varepsilon^{S N *} \lambda\right)+\alpha(2 Q-w)+2 s}{4} \\
\underline{\gamma\left[\alpha c(2+\lambda)+2 \lambda\left(p_{b}+c-\delta-\alpha Q-s-w\right)-2 e_{0} \gamma \lambda(1-\lambda)-2 \alpha w\right]}\end{array}$ & $\begin{array}{l}\frac{p_{b}+c-\delta+e_{0} \gamma\left(1-\lambda+\varepsilon^{S R *} \lambda\right)+\alpha Q+s}{2} \\
\gamma p_{b} \lambda\left(\beta^{2}-4 \eta\right)+\gamma \lambda\left(\beta^{2}-4 \eta\right)\left(c-\delta-e_{0} \gamma+e_{0} \gamma \lambda-s\right)+\alpha\left(w+\lambda Q-\beta^{2} \lambda Q\right)\end{array}$ \\
\hline$\pi_{r}^{*}$ & $\begin{array}{l}\frac{(Q-w)^{2}}{4} \\
-\underline{\left[2\left(p_{b}-\delta-\alpha Q-s\right)+(2+\alpha) c-2 e_{0} \gamma(1-\lambda)-2(2+\lambda) e_{0} \gamma \varepsilon^{S N *}-\alpha w\right]^{2}}\end{array}$ & $-\frac{\eta\left(e_{0} \varepsilon^{S R *} \gamma+Q-w\right)^{2}}{\beta^{2}\left(\beta^{2}-4 \eta\right)\left(\gamma^{2} \lambda^{2}-2 \alpha \mu\right)}$ \\
\hline$\pi_{m}^{*}$ & $\begin{array}{l}-\frac{\left(e_{0} \varepsilon^{S N *}\right)^{2} \mu}{2}-\left[-2\left(p_{b}-\delta-\alpha Q-s\right)-(2-\alpha) c+2 e_{0} \gamma(1-\lambda)+2 \lambda e_{0} \gamma \varepsilon^{S N *}-\alpha w\right] \\
* \frac{\left[2\left(p_{b}-\delta-\alpha Q-s\right)+(2+\alpha) c-2 e_{0} \gamma(1-\lambda)-2 e_{0} \gamma \lambda \varepsilon^{S N *}-\alpha w\right]}{16 \alpha} \\
(c-w) \\
* \frac{\left[2\left(p_{b}-\delta-2 Q-\alpha Q-s\right)+(2+\alpha) c-2 e_{0} \gamma(1-\lambda)-2(2+\lambda) e_{0} \gamma \varepsilon^{S N *}+w(4-\alpha)\right]}{Q}\end{array}$ & $\begin{array}{l}\frac{\left[p_{b}+c-\delta-e_{0} \gamma\left(1-\lambda+\varepsilon^{S R *} \lambda\right)-\alpha Q-s\right]^{2}}{4 \alpha} \\
-\frac{\left(\varepsilon^{S R *} e_{0}\right)^{2} \mu}{2}+\frac{8 \eta(c-w)\left(e_{0} \varepsilon^{S R *} \gamma+Q-w\right)}{4\left(\beta^{2}-4 \eta\right)}\end{array}$ \\
\hline$E^{*}$ & $\begin{array}{l}e_{0}\left[1-\left(1-\varepsilon^{S N *}\right) \lambda+\varepsilon^{S N *}\right]^{8} \\
* \frac{\left[-2\left(p_{b}-\delta-\alpha Q-s\right)-(2+\alpha) c+2 e_{0} \gamma(1-\lambda)+2 \lambda e_{0} \gamma \varepsilon^{S N *}-\alpha w\right]}{4 \alpha} \\
+4 e_{0} \varepsilon^{S N *}\left(e_{0} \gamma \varepsilon^{S N *}-w\right)^{2}\end{array}$ & $\begin{array}{l}\frac{e_{0}\left[\left(1-\varepsilon^{S R *}\right) \lambda-1\right]\left[p_{b}+c-\delta-e_{0} \gamma\left(1-\lambda+\varepsilon^{S R *} \lambda\right)-\alpha Q-s\right]}{2 \alpha} \\
-\frac{2 e_{0} \varepsilon^{S R *} \eta\left(e_{0} \varepsilon^{S R *} \gamma+Q-w\right)}{\beta^{2}-4 \eta}\end{array}$ \\
\hline
\end{tabular}

Proposition 3. $\frac{\partial \varepsilon^{S R *}}{\partial v}=0, \varepsilon^{S R *}$ is not affected by $v ; E^{S R *}$ increases monotonically with $v$.

Proposition 3 manifests that in the government subsidy policy setting, the manufacturer's optimal carbon emission reduction level will not change with the change of the retailer's investment in CSR, and the environmental benefits of the supply chain will gradually increase with the retailer's investment in CSR. It can be seen that the retailer increases the sales scale by increasing the level of CSR investment and bringing greater supply chain environmental benefits to the supply chain.

Proposition 4. In the government subsidy policy setting, we contrast Model SN with Model SR and obtain:

1. $\quad \varepsilon^{S N *}>\varepsilon^{S R *}$. When $v<\hat{v}_{1}^{S}, E^{S N *}>E^{S R *}$; when $v \geq \hat{v}_{1}^{S}, E^{S N *} \leq E^{S R *}$.

2. When $v \geq \hat{v}_{2}^{S}, p_{n}^{S N *} \geq p_{n}^{S R *}$; when $v<\hat{v}_{2}^{S}, p_{n}^{S N *}<p_{n}^{S R *}$.

$$
\hat{v}_{2}^{S}=\frac{\alpha \mu\left\{2\left[p_{b}-\delta-(1-\lambda) e_{0} \gamma-\alpha Q-s\right]-w \alpha+(2+\alpha) c\right\}}{\beta\left(-2 \gamma^{2} \lambda^{2}+2 \alpha \mu\right)}
$$

3. When $\lambda>\frac{\sqrt{\alpha \mu}}{\gamma}, p_{r}^{S N *}>p_{r}^{S R *}$; when $\lambda \leq \frac{\sqrt{\alpha \mu}}{\gamma}, p_{r}^{S N *} \leq p_{r}^{S R *}$.

4. When $v<\hat{v}_{3}^{S}, \pi_{m}^{S N *}>\pi_{m}^{S R *}$; when $v \geq \hat{v}_{3}^{S}, \pi_{m}^{S N *} \leq \pi_{m}^{S R *}$,

$$
\hat{v}_{3}^{S}=\frac{\alpha\left\{2 c \gamma^{2} \lambda+(4+\alpha) c \mu+4 \mu\left[p_{b}-\delta-(1-\lambda) e_{0} \gamma-\alpha Q-s\right]-w\left(2 \gamma^{2} \lambda-\alpha \mu\right)\right\}}{4 \beta\left(\gamma^{2} \lambda^{2}-2 \alpha \mu\right)} .
$$

when $v \geq \hat{v}_{4}^{S}, \pi_{r}^{S N *} \geq \pi_{r}^{S R *} ;$ when $v<\hat{v}_{4}^{S}, \pi_{r}^{S N *}<\pi_{r}^{S R *}$

The proof and some threshold expressions are shown in Appendix B.

Proposition 4 part 1 demonstrates that when the government subsidy policy is enforced, the retailer's implementation of CSR activities will cause the manufacturer to reduce their investment in low-carbon production and decline the level of carbon emissions reduction. Therefore, there is a threshold of CSR investment level, $\hat{v}_{1}^{S}$. Only when the retailer's investment in CSR is higher than threshold $\hat{v}_{1}^{S}$, CSR activities can increase sales to compensate for the loss of environmental benefits caused by the decrease of carbon emissions reduction, thereby increasing the overall environmental benefits of the supply chain.

Part 2 manifests that when the CSR input level is lower than threshold $\hat{v}_{2}^{S}$, the increase in revenue brought by the retailer's implementation of CSR activities is lower than the input 
cost. Therefore, the retailer must share the input costs of CSR activities with consumers through a cost pass. When the CSR input level is higher than threshold $\hat{v}_{2}^{S}$, the retailer can achieve the purpose of increasing profits by implementing CSR activities.

Part 3 manifests that under the government subsidy policy, the manufacturer expands the scale of recycling to increase profits. Therefore, when the retailer implements CSR activities, the manufacturer with lower low-carbon properties of re-products will lower the price of re-products, while the manufacturer with better low-carbon properties of reproducts will raise the price of re-products. The evaluation criteria of re-product low-carbon property are determined by consumers' low-carbon preference coefficient, the carbon emission reduction input cost coefficient, and the discount on consumers' willingness to pay for re-products. Moreover, the higher the consumers' low-carbon preference coefficient, the more conducive it is for the manufacturer to reduce the price of re-products.

Part 4 reveals an interesting outcome whereby under the government subsidy policy, there are two thresholds for CSR investment levels; when the retailer's CSR investment level exceeds threshold $\hat{v}_{3}^{S}$, the retailer's implementation of CSR activities will increase the manufacturer's profits. Meanwhile, when the CSR investment level does not exceed threshold $\hat{v}_{4}^{S}$, the retailer can increase the profit by implementing CSR activities. Through the analysis of two thresholds, Inference 2 can be obtained.

Inference 2. In the government subsidy policy setting, when $\eta<\hat{\eta}^{S}$, there is an ideal range of CSR investment levels: $\left[\hat{v}_{1}^{S}, \hat{v}_{2}^{S}\right]$.

From Inference 2, we know that under the government subsidy policy, when the retailer's CSR investment level is within a certain range, the implementation of CSR activities is beneficial to the retailer and the manufacturer to achieve the ideal state of the retailer's CSR investment level, where the implementation of CSR activities will not harm the interests of any members of the supply chain.

\section{Numerical Simulation}

\subsection{Difference Comparison}

In this section, we conduct comparative analyses of CSR investment levels' effects on supply chain performance and environmental benefits in two settings. According to the proportion of the data in [54], combined with the setting of the parameters and variable relationships in the assumption part of the model and the conditions for the existence of the optimal solution of the model, we set the parameter values as follows: $Q=100, e_{0}=3.8$, $c=20, \delta=8, w=65.5, \alpha=0.62, \mu=150, \lambda=0.8, \gamma=4, s=t=3, p_{b}=3, \eta=200, \beta=6$. Therein, the carbon tax rate $t$ and the government subsidy $s$ are set to be equivalent, which guarantees the single-variable principle.

Differences in corporate decision-making, supply chain performance, and environmental benefits for models that implement or do not implement CSR activities in the two settings are presented in Table 5.

Table 5. The difference of each performance in the two settings.

\begin{tabular}{|c|c|c|c|c|c|c|c|c|}
\hline$v$ & 0.1 & 0.2 & 0.3 & $v^{\mathrm{SR}^{*}}=0.32068$ & $v^{\mathrm{TR}^{*}}=0.354096$ & 0.4 & 0.5 & 0.6 \\
\hline$\Delta \pi_{m}^{T *}$ & -12.5589 & -25.1249 & -37.6982 & -40.2992 & -44.5028 & -50.2786 & -62.8662 & -75.461 \\
\hline$\Delta \pi_{m}^{S *}$ & 696.983 & 683.333 & 669.683 & 666.86 & 662.299 & 656.033 & 642.383 & 628.733 \\
\hline$\Delta \pi_{r}^{T *}$ & -12.2662 & -20.7321 & -25.3977 & -25.8883 & -26.3376 & -26.263 & -23.3279 & -16.5925 \\
\hline$\Delta \pi_{r}^{S *}$ & -294.825 & -301.309 & -303.973 & -304.047 & -303.821 & -302.816 & -297.84 & -289.044 \\
\hline$\Delta \varepsilon^{T *}$ & -0.00210 & -0.00420 & -0.00630 & -0.00674 & -0.00744 & -0.00841 & -0.01051 & -0.01261 \\
\hline$\Delta \varepsilon^{S *}$ & 0.06758 & 0.06758 & 0.06758 & 0.06758 & 0.06758 & 0.06758 & 0.06758 & 0.06758 \\
\hline$\Delta E^{T *}$ & -1.36994 & -2.74540 & -4.12636 & -4.41262 & -4.87569 & -5.51282 & -6.90479 & -8.30227 \\
\hline$\Delta E^{S *}$ & 73.0275 & 72.5616 & 72.0957 & 71.9993 & 71.8436 & 71.6298 & 71.1638 & 70.6979 \\
\hline$\Delta p_{n}^{T *}$ & -0.31597 & -0.63194 & -0.94791 & -1.01325 & -1.11884 & -1.26388 & -1.57985 & -1.89582 \\
\hline$\Delta p_{n}{ }^{S *}$ & -17.2705 & -17.5705 & -17.8705 & -17.9326 & -18.0328 & -18.1705 & -18.4705 & -18.7705 \\
\hline$\Delta p_{r}^{T *}$ & -0.00319 & -0.00639 & -0.00958 & -0.01024 & -0.01131 & -0.01278 & -0.01597 & -0.01916 \\
\hline$\Delta p_{r}{ }^{S *}$ & -6.64161 & -6.64161 & -6.64161 & -6.64161 & -6.64161 & -6.64161 & -6.64161 & -6.64161 \\
\hline
\end{tabular}


The data in Table 5 is in line with Propositions 1 to 4 . Through comparison, we find that compared with carbon tax policy, it is under the government subsidy policy that the CSR investment level has a more significant impact on supply chain performance, members' decision-making, and environmental benefits. Under the carbon tax policy, CSR activities have a relatively mild positive impact on environmental benefits and supply chain performance. Under the government subsidy policy, the implementation of CSR activities greatly increases the retailer's profit, but it also reduces the profit of the manufacturer greatly, which is not conducive to coordination among supply chain members. Therefore, for the supply chain that does not have an ideal range of CSR investment levels, the implementation of a carbon tax policy will help reduce the burden on the environment, increase government tax revenue, and maintain supply chain coordination.

It can be seen from Table 5 that under the government subsidy policy, the level of CSR input has a significant impact on supply chain performance and will aggravate the conflict of interest among supply chain members; in contrast, under the carbon tax policy, CSR activities have a moderate but positive impact on environmental benefits and supply chain performance.

\subsection{Sensitivity Analysis}

To further analyze the impact of CSR activities on supply chain performance, emission reduction decisions, and environmental benefits under two carbon regulatory policies, this section uses the consumers' CSR sensitivity coefficient as a variable to explore the impact of CSR market-level factors on the emission reduction effects and supply chain performance. We also numerically show our comparison results between Setting $\mathrm{T}$ and Setting S.

The trajectories of CSR activities with respect to consumer CSR sensitivity under the two carbon regulatory policies are shown in Figure 3.

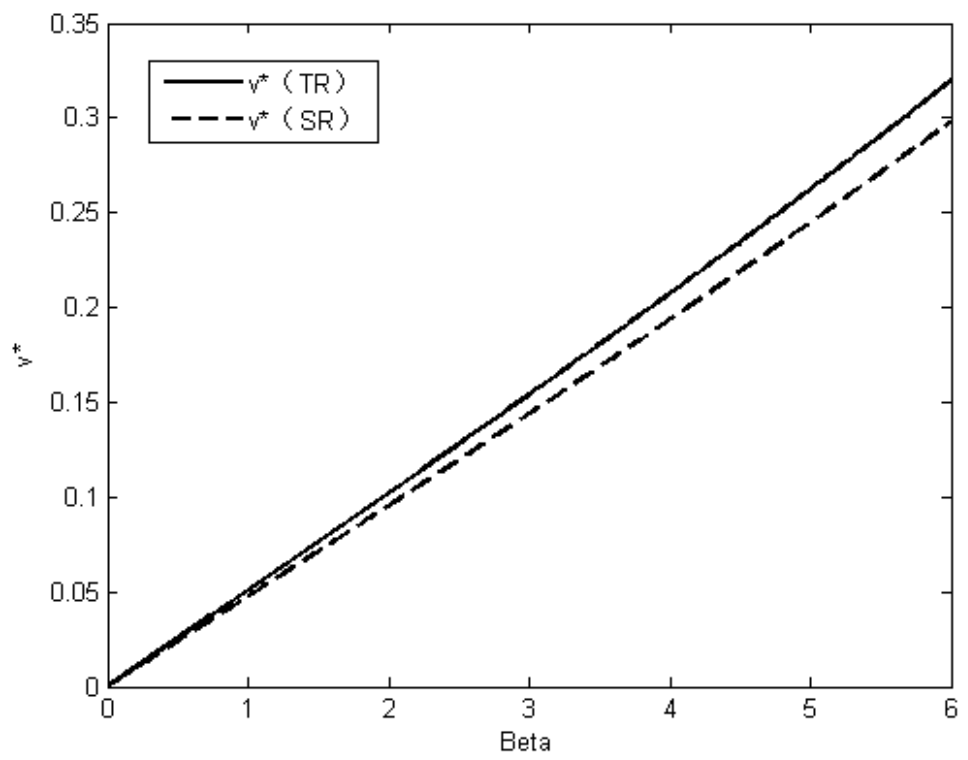

Figure 3. Function image of the retailer's optimal CSR investment levels $\left(v^{*}\right)$.

Figure 3 shows that under the two carbon regulatory policies, the retailer's optimal CSR investment level increases monotonically regarding the consumer's CSR sensitivity coefficient. When consumers are more sensitive to CSR, the level of CSR investment under the carbon tax policy is slightly higher than that under the government subsidy policy. Therefore, the implementation of carbon tax policies is more conducive to stimulating the retailer's awareness of social responsibility and guiding retail companies to implement CSR activities.

Through the analysis of Figure 3, it can be seen that the higher the consumer's sensitivity to CSR, the higher the retailer's optimal CSR activity investment level. Under the 
carbon tax policy, the retailer's CSR awareness is stronger, and the retail enterprise is more vigorous in carrying out CSR activities.

Under the two carbon regulatory policies, the change trajectory of carbon emission reduction level and supply chain environmental benefit on consumer CSR sensitivity are shown in Figures 4 and 5, respectively.

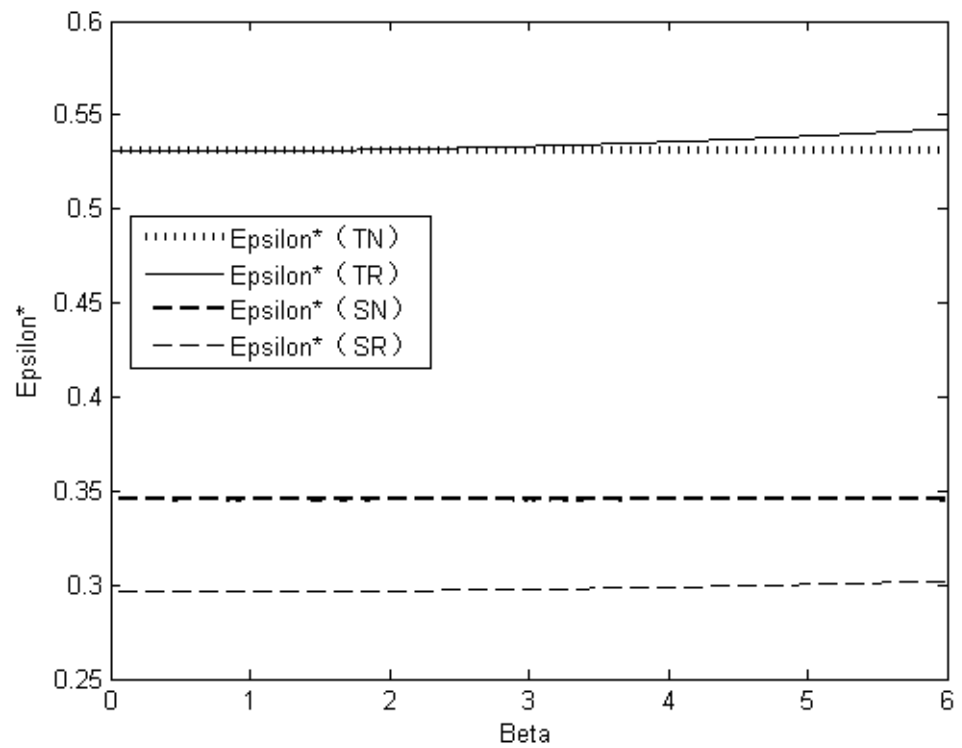

Figure 4. Function image of optimal carbon reduction levels $\left(\varepsilon^{*}\right)$.

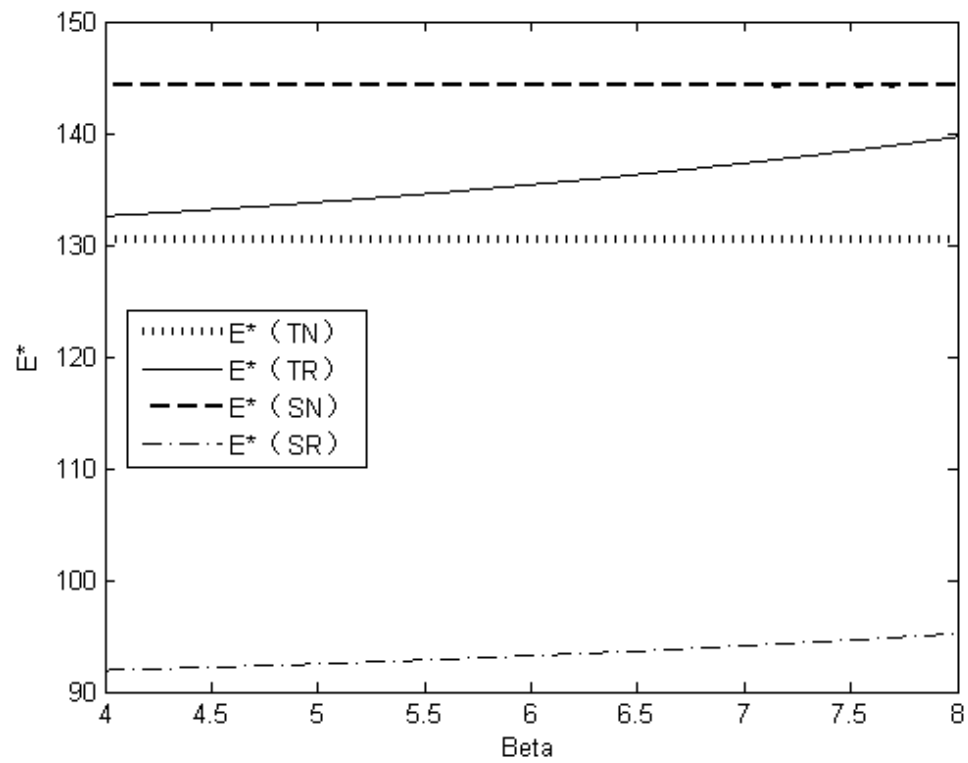

Figure 5. Function image of optimal environmental benefits $\left(E^{*}\right)$.

Figures 4 and 5 reveal that in Model TR and Model SR, the manufacturer's carbon emission reduction level and the environmental benefits of the supply chain increase with the consumer's CSR sensitivity coefficient. Combining the data in Figure 4 and Table 5, we find an interesting outcome that under the carbon subsidy policy, the level of carbon emission reduction is only affected by the retailer's CSR decision-making, which has nothing to do with the specific decision-making level and the consumers' CSR sensitivity; the price of the re-products is the same. We conclude that in a non-competitive dualchannel closed-loop supply chain, when the government enforces the subsidy policy, the manufacturer's carbon emission reduction level decision and the re-products pricing decision are only related to whether the retailer invests in CSR but has nothing to do with 
the investment level. Figure 5 shows that under the carbon tax policy, the environmental benefits of the supply chain increase with the retailer's implementation of CSR activities, while under the government subsidy policy, it reduces greatly. Therefore, starting from the environmental benefits of the supply chain, the carbon tax policy applies to the supply chain that implements CSR activities, while the government subsidy policy applies to the supply chain that does not implement CSR activities.

To sum up, it can be seen that under the carbon subsidy policy, the impact of the retailer's CSR decision on the manufacturer's decision is constant, which does not vary with the level of CSR input and the consumer's CSR sensitivity. Under the carbon tax policy, CSR activities are conducive to improving the level of carbon emission reduction and increasing the environmental benefits of the supply chain.

Under the two carbon regulatory policies, the trajectories of retailers' profits and manufacturers' profits with respect to consumer CSR sensitivity are shown in Figures 6 and 7, respectively.

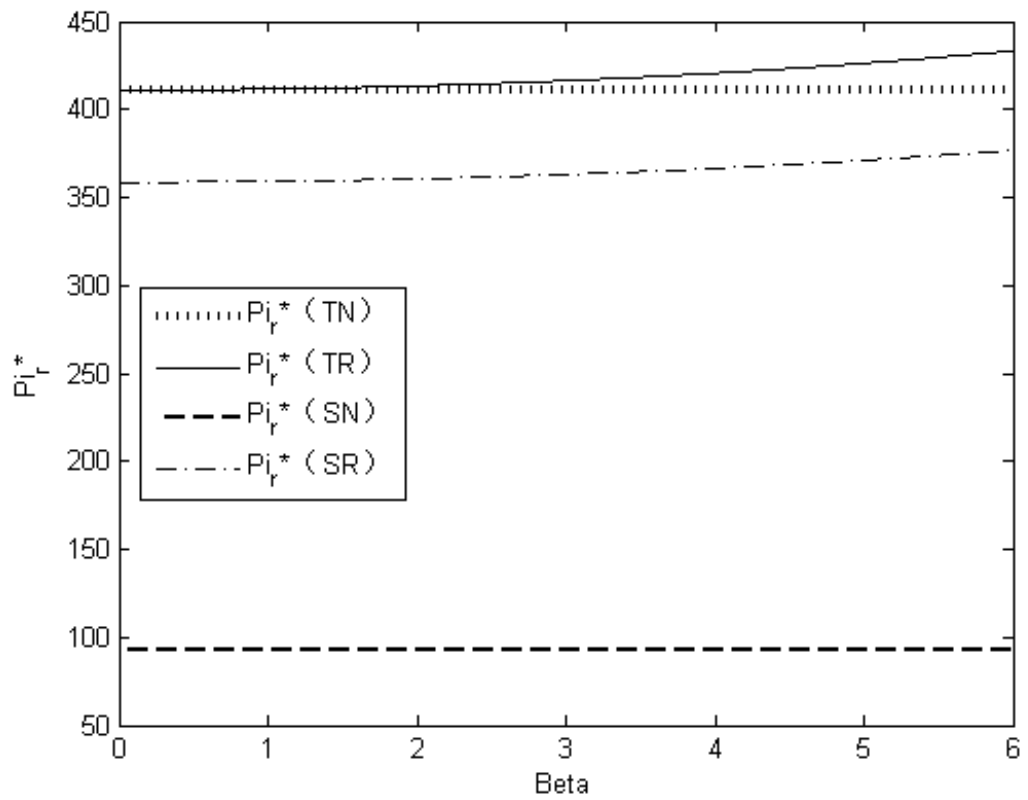

Figure 6. Function image of optimal retailer's profit $\left(\pi_{r}^{*}\right)$.

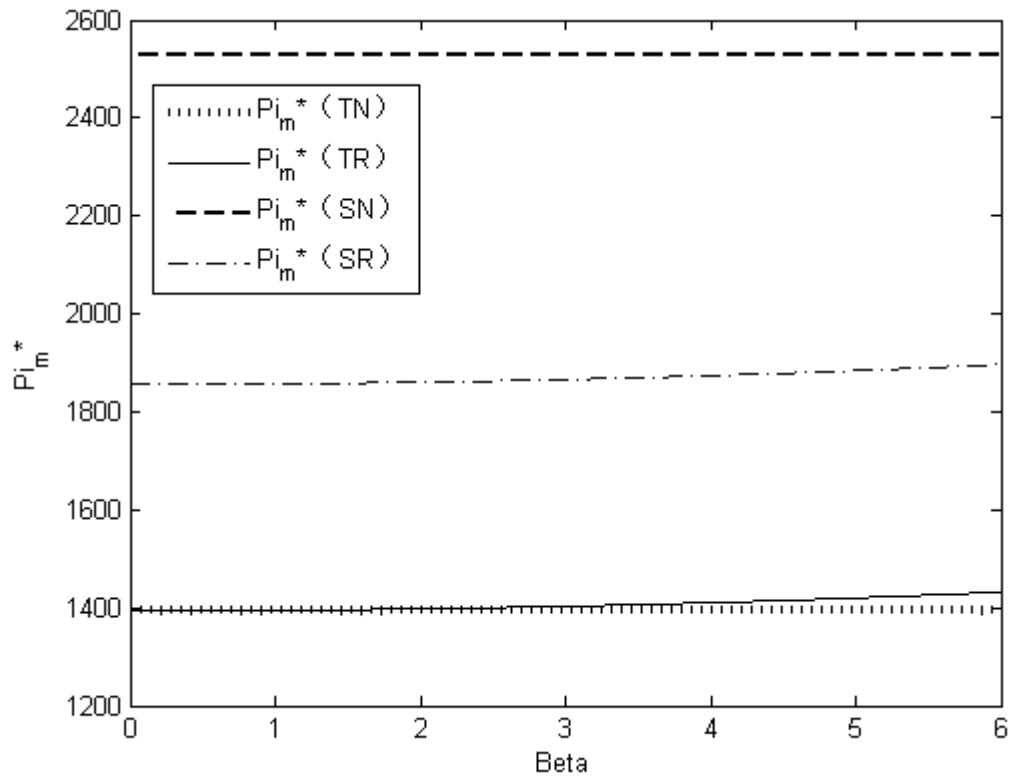

Figure 7. Function image of optimal manufacturer's profit $\left(\pi_{m}^{*}\right)$. 
Figures 6 and 7 reveal that in Models TR and SR, profits of closed-loop supply chain members increase slightly with the consumer's CSR sensitivity coefficient. The profit of the retailer under the carbon tax policy is always higher than that under the government subsidy policy, which is the opposite of the manufacturer's profit. Hence, the carbon tax policy is conducive to incentivizing the retailer to implement CSR activities and increasing the manufacturer's enthusiasm for low-carbon emission reduction, thereby increasing the environmental benefits of the supply chain, promoting benign cooperation among supply chain members, and maintaining supply chain coordination.

Based on the analysis of Figures 5-7, it can be seen that under the carbon subsidy policy, for a supply chain where the ideal range of CSR investment level cannot be achieved, the implementation of CSR activities that can increase the retailer's profit is not conducive to supply chain coordination and low-carbon emission reduction. Therefore, the retailer should reasonably choose the CSR implementation approach to ensure that the CSR input cost coefficient is in the ideal range, which is conducive to eliminating profit conflicts between supply chain members.

\section{Industrial Implications}

The development of the automobile industry has promoted the progress of society; however, it has also consumed a lot of natural resources and polluted the atmosphere. With the strengthening of environmental awareness and the aggravation of environmental crises, countries have increasingly stringent controls on carbon emissions and fuel consumption indicators. More and more countries have implemented policies to support the development of new energy vehicles and have issued timetables for the abolition of fuel vehicles [55]. For example, the British and French governments had successively announced that they will ban the sale of new petrol and diesel vehicles from 2040. Under such circumstances, to seek breakthroughs and new development, many companies turn their attention to the new energy vehicle industry [56]. In this section, we combine the situation of the new energy vehicle industry to illustrate the practical significance of the results of this paper.

Under the carbon tax policy, the implementation of CSR activities will not only increase the profits of new energy vehicle retailers but also help new energy vehicle manufacturers to develop low-carbon production technologies, improve the green level of new energy vehicles, and drive green technology innovation of the entire industry, thereby improving the market competitiveness of new energy vehicles and expanding the market space of the industry. It should be noted that the development of the new energy vehicle industry requires a large amount of financial support, and various new technologies are still in the process of continuous development. The scale of production and the age of enterprises have a significant impact on the innovation input and output of enterprises [35]. Although the carbon tax policy can guide new energy vehicle retailers to actively undertake CSR and improve the level of green production technology in the new energy vehicle industry, as a punitive policy, it is not suitable for new entrants with relatively little capital or small production scale.

Contrary to the carbon tax policy, the government subsidy policy can expand the recycling scale of new energy vehicles from the demand side, improve the remanufacturing technology level of new energy vehicles, and thus increase the utilization rate of resources in the new energy vehicle industry. However, the subsidy policy is not conducive to the coordination of the supply chain of new energy vehicles. When the government implements subsidies, there are conflicts between new energy vehicle retailers and manufacturing decisions. Specifically, new energy vehicle retailers choose to implement CSR activities to increase profits, which damages the manufacturer's profits. For large-scale and experienced new energy vehicle enterprises, the profit conflict caused by the subsidy policy is more significant, so government subsidies do not apply to the new energy vehicles remanufactured by such enterprises.

To sum up, when new energy vehicle retailers implement CSR, the government subsidy policy applies to the supply chain of new energy vehicles with smaller production scale 
and less seniority, which can not only support the development of small and medium-sized enterprises but also weaken the profit conflict of members in the supply chain; in contrast, the carbon tax policy applies to new energy vehicle enterprises with large-scale production and more seniority, which is conducive to guiding large enterprises to play their role as industry leaders and expand the market space of new energy vehicles.

\section{Conclusions and Management Insights}

\subsection{Conclusions}

Based on the two carbon regulatory settings, we respectively construct the optimal decision models where the retailer implements CSR activities or not. We also analyze the impact of the implementation of CSR activities on the supply chain performance and environmental benefits and obtain the following main conclusions:

(1) The carbon tax policy is more conducive to stimulating the retailer's awareness of social responsibility and guiding retail companies to implement CSR activities. (2) The retailer chooses a CSR implementation method with a low-cost coefficient, which is conducive to eliminating profit conflicts among supply chain members. (3) Starting from the environmental benefits of the supply chain, the carbon tax policy is applicable to the supply chain where the retailer implements CSR activities, while the subsidy policy is applicable to the supply chain where the retailer does not implement CSR activities. (4) For the supply chain where the ideal range of CSR investment level cannot be achieved, the implementation of a carbon tax policy will help maintain supply chain coordination. (5) The carbon tax policy can inspire the manufacturer to pay attention to the emission reduction properties of re-products, thereby expanding the scale of remanufacturing and promoting the development of the circular economy.

\subsection{Management Insights}

Based on the above conclusions, the following management enlightenment is obtained:

(1) Before formulating and adjusting carbon regulatory policies, governments should fully consider the decision-making thresholds of supply chain members to ensure that the policy plays the best role. (2) When making decisions about the level of CSR investment, retailers should fully consider that other members of the supply chain can achieve supply chain coordination and maximize supply chain value. (3) Manufacturers should pay attention to the economic and environmental benefits brought by carbon emission reduction and remanufacturing and actively innovate green production technologies and remanufacturing technologies to maximize policy dividends into development motivation.

\subsection{Research Limitations and Prospects}

1. In the modeling process of this paper, to highlight the research results, we constructed a one-stage, demand-driven model without considering the quantity and quality restrictions of old products. In future research on the two-stage closed-loop supply chain, we will fully consider the constraints of recycling the quality and quantity of old products.

2. In the process of exploring the impact of CSR, this paper only considered consumers' preferences for CSR. In future research, we will further explore the more diverse impacts of CSR.

Author Contributions: Conceptualization, N.L. and F.Z.; methodology, N.L.; software, N.L.; validation, N.L.; formal analysis, N.L.; investigation, F.Z.; resources, F.Z.; data curation, N.L.; writingoriginal draft preparation, N.L.; writing-review and editing, F.Z.; visualization, N.L.; supervision, F.Z.; project administration, F.Z.; funding acquisition, F.Z. All authors have read and agreed to the published version of the manuscript.

Funding: This research was funded by the National Natural Science Foundation of China, grant number 71971210 .

Institutional Review Board Statement: Not applicable. 
Informed Consent Statement: Not applicable.

Data Availability Statement: The data presented in this study are available in "The Impact of CSR on the Performance of a Dual-channel Closed-loop Supply Chain under Two Carbon Regulatory Policies".

Acknowledgments: The authors thank the journal for providing a platform for the article and thank the funding institutions.

Conflicts of Interest: The authors declare no conflict of interest. The funders had no role in the design of the study; in the collection, analyses, or interpretation of data; in the writing of the manuscript, or in the decision to publish the results.

\section{Appendix A. Existence of a Unique Nash Equilibrium under Setting $\mathrm{T}$ and $\mathrm{S}$}

\section{Model TN}

In Model TN, the second derivative of the retailer's profit function according to the retail price of the new product is $\frac{d^{2} \pi_{r}^{T N}}{d p_{n}^{T N 2}}=-2$, so the retailer's profit function is concave and has a maximum value. The maximum point $p_{n}^{T N *}\left(p_{r}^{T N}, \varepsilon^{T N}\right)$ is obtained by solving. Additionally, we put it into Equation (1) to get the Hessian matrix of the manufacturer's profit function:

$$
H\left(\pi_{m}^{T N}\right)=\left(\begin{array}{cc}
-\frac{2}{\alpha} & \frac{e_{0} \lambda(\gamma-t)}{\alpha} \\
\frac{e_{0} \lambda(\gamma-t)}{\alpha} & \frac{e_{0}^{2}\left[\alpha(\gamma t-\mu)+2 \gamma \lambda^{2} t\right]}{\alpha}
\end{array}\right)
$$

It can be seen that when $2\left[\alpha(\mu-\gamma t)-2 \gamma \lambda^{2} t\right]>\lambda^{2}(\gamma-t)^{2}, \pi_{m}^{T N}$ is a concave function about $p_{r}, \varepsilon$. According to the inverse induction method, the optimal solution of Model TN can be obtained by solving.

Model TR

In Model TR, the Hessian matrix of the retailer's profit function $\pi_{r}^{T R}$ on the retail price of new products $p_{n}$ and the CSR investment level $v$ of the retailer is as follows:

$$
H\left(\pi_{r}^{T R}\right)=\left(\begin{array}{cc}
-2 & \beta \\
\beta & -2 \eta
\end{array}\right)
$$

Therefore, when $\beta^{2}<4 \eta$, the retailer's profit function is concave, which has a maximum value. The maximum value points, $p_{n}^{T R *}\left(p_{r}^{T R}, \varepsilon^{T R}\right), v^{T R *}\left(p_{r}^{T R}, \varepsilon^{T R}\right)$, are obtained by solving, and it is brought into Equation (4) to obtain the Hessian matrix of the manufacturer's profit function according to $p_{r}, \varepsilon$ :

$$
H\left(\pi_{m}^{T R}\right)=\left(\begin{array}{cc}
-\frac{2}{\alpha} & \frac{e_{0} \lambda(\gamma-t)}{\alpha} \\
\frac{e_{0} \lambda(\gamma-t)}{\alpha} & e_{0}^{2}\left[\frac{2 \gamma \lambda^{2} t}{\alpha}-\frac{4 \gamma \eta t}{\beta^{2}-4 \eta}-\mu\right]
\end{array}\right)
$$

It can be seen that when $\frac{8 \alpha \gamma \eta t}{\beta^{2}-4 \eta}+2 \alpha \mu>\lambda^{2}(\gamma+t)^{2}, \pi_{m}^{T R}$ is a concave function of $p_{r}, \varepsilon$. According to the inverse induction method, the optimal solution of Model TR can be obtained by solving.

Model SN

In Model SN, the second derivative of the retailer's profit function $\pi_{r}^{S N}$ according to the retail price of the new product is $\frac{d^{2} \pi_{r}^{S N}}{d p_{n}^{S N 2}}=-2$, so the retailer's profit function is concave and has a maximum value. The maximum point $p_{n}^{S N *}\left(p_{r}^{S N}, \varepsilon^{S N}\right)$ is obtained by solving. Additionally, we put it into Equation (8) to get the Hessian matrix of the manufacturer's profit function:

$$
H\left(\pi_{m}^{S N}\right)=\left(\begin{array}{cc}
-\frac{2}{\alpha} & \frac{e_{0} \gamma \lambda}{\alpha} \\
\frac{e_{0} \gamma \lambda}{\alpha} & -e_{0}^{2} \mu
\end{array}\right)
$$


It can be seen that when $2 \mu \alpha>\gamma^{2} \lambda^{2}, \pi_{m}^{S N}$ is a concave function of $p_{r}, \varepsilon$. According to the inverse induction method, the optimal solution of Model SN can be obtained by solving.

Model SR

In Model SR, the Hessian matrix of retailer's profit function $\pi_{r}^{S R}$ on the retail price of new products $p_{n}$ and the CSR investment level $v$ of retailer is as follows:

$$
H\left(\pi_{r}^{S R}\right)=\left(\begin{array}{cc}
-2 & \beta \\
\beta & -2 \eta
\end{array}\right)
$$

Therefore, when $\beta^{2}<4 \eta$, the retailer's profit function is concave, which has a maximum value. The maximum value points $p_{n}^{S R *}\left(p_{r}^{S R}, \varepsilon^{S R}\right), v^{S R *}\left(p_{r}^{S R}, \varepsilon^{S R}\right)$ are obtained by solving, and it is brought into Equation (11) to obtain the Hessian matrix of the manufacturer's profit function according to $p_{r}, \varepsilon$ :

$$
H\left(\pi_{m}^{S R}\right)=\left(\begin{array}{cc}
-\frac{2}{\alpha} & \frac{e_{0} \gamma \lambda}{\alpha} \\
\frac{e_{0} \gamma \lambda}{\alpha} & -e_{0}^{2} \mu
\end{array}\right)
$$

It can be seen that when $2 \mu \alpha>\gamma^{2} \lambda^{2}, \pi_{m}^{S R}$ is a concave function of $p_{r}, \varepsilon$. According to the inverse induction method, the optimal solution of Model SR can be obtained by solving.

Proof of Theorems 1 and 2. According to the conditions for the existence of the optimal equilibrium solution of Model TN and Model TR, Theorem 1 can be obtained. According to the conditions for the existence of the optimal equilibrium solution of the Model SN and Model SR, Theorem 2 can be obtained.

\section{Appendix B. Thresholds Expression}

$$
\begin{aligned}
& \hat{v}_{4}^{S}=\alpha * \\
& \left\{\alpha^{2} \gamma \mu(c-2 Q-w)[c(2+\lambda)-2 w-\lambda(2 Q+w)]\right. \\
& +2 \gamma \lambda\left\{2 p_{b}^{2} \mu+2 \mu\left[(1-\lambda) e_{0} \gamma+(\delta+s)\right]^{2}+c^{2}\left[\gamma^{2} \lambda(3+\lambda)+2 \mu(1+2 \lambda)\right]\right. \\
& +\left(3 \gamma^{2}+4 \mu\right)(\delta+s) \lambda w+\left(3 \gamma^{2}+2 \mu\right)(1-\lambda) e_{0} \gamma \lambda w+\gamma^{2} \lambda^{2}(2 w-Q) w \\
& +p_{b}\left[3(c-w) \gamma^{2} \lambda-4(\delta+s) \mu-4 e_{0} \gamma \mu(1-\lambda)+4 c \mu(1+\lambda)-4 \lambda \mu w\right] \\
& \left.-c\left[-\gamma^{2} \lambda^{2} Q+(s+\delta)\left[3 \gamma^{2} \lambda+4(1+\lambda) \mu\right]+e_{0} \gamma(1-\lambda)\left[3 \gamma^{2} \lambda+2(2+\lambda) \mu\right]+3(1+\lambda) \gamma^{2} \lambda w+4 \lambda \mu w\right]\right\} \\
& +2 \alpha\left\{4(\delta+s) \gamma \lambda Q \mu+4(1-\lambda) e_{0} \gamma^{2} \lambda Q \mu+c^{2} \mu\left[\gamma^{3} \lambda(3+\lambda)+\gamma\left(2+4 \lambda+\lambda^{2}\right)\right]+3 \gamma^{3} \lambda^{2} Q w+2(1+\lambda) \delta \gamma \mu w\right. \\
& +2\left(1-\lambda^{2}\right) e_{0} \gamma^{2} \mu w+2(1+2 \lambda) \gamma \lambda Q \mu w+2(1+\lambda) \gamma s \mu w+4(1-\lambda) e_{0} \mu^{2} w+(3+\lambda) \gamma^{3} \lambda w^{2}+\gamma \lambda^{2} \mu w^{2} \\
& -2 p_{b} \gamma \mu(2 \lambda Q+w+\lambda w)-c\left\{2 e_{0} \gamma^{2}\left(\lambda^{2}-1\right) \mu+4 e_{0}(1-\lambda) \mu^{2}+\gamma^{3} \lambda(3 \lambda Q+6 w+2 \lambda w)\right. \\
& \left.\left.\left.+2 \gamma \mu\left[\left(\delta-p_{b}+s\right)(1+\lambda)+(3+2 \lambda) \lambda Q+(1+\lambda)^{2} w\right]\right\}\right\}\right\} \\
& /\left\{4 \beta \gamma\left(\gamma^{2} \lambda^{2}-2 \alpha \mu\right)\left[\lambda\left(p_{b}+c-\delta-e_{0} \gamma+e_{0} \gamma \lambda-s\right)+\alpha(c-\lambda Q-w)\right]\right\} \\
& \hat{v}_{3}^{S}=\frac{1}{2\left(\beta^{2}-4 \eta\right)\left(\gamma^{2} \lambda^{2}-2 \alpha \mu\right)} \\
& \left\{-2\left(p_{b}+c-\delta-e_{0} \gamma+e_{0} \gamma \lambda-\alpha Q+\lambda Q-s\right) \beta \gamma^{2} \lambda+4 \alpha \beta Q \mu+2 \alpha \beta \gamma^{2}(w-c)+(2 \beta w-1) \gamma^{2} \lambda^{2}-\frac{4 \alpha \beta \mu w}{\sqrt{A}}\right\} \\
& +\frac{2 \alpha \mu}{\sqrt{A}}
\end{aligned}
$$




$$
\begin{aligned}
& A=\frac{1}{\gamma^{2} \lambda^{2}-2 \alpha \mu} \\
& \left\{\alpha^{4}\left(\beta^{2}-4 \eta\right) \mu^{2}(c-2 Q-w)^{2}+4 \beta^{2} \gamma^{4} \lambda^{2}\left(p_{b}+c-\delta-e_{0} \gamma+e_{0} \gamma \lambda+\lambda Q-s-\lambda w\right)^{2}\right. \\
& -2 \alpha^{3}\left(\beta^{2}-4 \eta\right) \mu(c-2 Q-w)\left(c \gamma^{2} \lambda+2 p_{b} \mu+2 c \mu-2 \delta \mu-2 e_{0} \gamma \mu+2 e_{0} \lambda \gamma \mu-2 s \mu-\gamma^{2} \lambda w\right) \\
& +4 \alpha \gamma^{2} \lambda\left(p_{b}+c-\delta-e_{0} \gamma+e_{0} \gamma \lambda+\lambda Q-s-\lambda w\right) \\
& \left\{4 \gamma^{2} \lambda \eta(w-c)+\beta^{2}\left[c \gamma^{2}(2+\lambda)+4 \mu(w-Q)-\gamma^{2}(2 \lambda Q+2 w+\lambda w)\right]\right\} \\
& +4 \alpha^{2}\left\{-4 \eta\left\{-p_{b}^{2} \mu^{2}-\left\{\left[\delta+(1-\lambda) e_{0} \gamma\right]+s\right\}^{2} \mu^{2}+c^{2}\left(\gamma^{4} \lambda-\gamma^{2} \lambda \mu-\mu^{2}\right)\right.\right. \\
& +\gamma^{4} \lambda^{2} Q w-\delta \gamma^{2} \lambda \mu w-(1-\lambda) e_{0} \gamma^{3} \lambda \mu w+(2 Q-s) \gamma^{2} \lambda \mu w+\gamma^{4} \lambda w^{2}-2 \gamma^{2} \lambda \mu w^{2} \\
& +p_{b} \mu\left[2 \delta \mu+2 e_{0} \gamma(1-\lambda) \mu+2 s \mu+\gamma^{2} \lambda w\right]+c\left[e_{0} \gamma^{3}(1-\lambda) \lambda \mu+2 e_{0} \gamma(1-\lambda) \mu^{2}\right. \\
& \left.\left.+2\left(-p_{b}+\delta+s\right) \mu^{2}-\gamma^{4} \lambda(\lambda Q+2 w)+\gamma^{2} \lambda \mu\left(-p_{b}+\delta-2 Q+s+3 w\right)\right]\right\} \\
& +\beta^{2}\left\{2 e_{0} \gamma(1-\lambda)\left(p_{b}-\delta-s\right) \mu^{2}+c^{2}\left(\gamma^{2}-\mu\right)\left[\gamma^{2}(1+\lambda)+\mu\right]-e_{0} \gamma^{3}(1-\lambda) \lambda \mu w\right. \\
& -\mu^{2}\left[\left(p_{b}-\delta-s\right)^{2}-4(Q-w)^{2}\right]+\gamma^{4}\left[(w+\lambda Q)^{2}+(w+\lambda) \lambda w\right] \\
& +c\left[e_{0} \gamma^{3}(1-\lambda) \lambda \mu+2 e_{0} \gamma(1-\lambda) \mu^{2}-2\left(p_{b}-\delta-s\right) \mu^{2}-\gamma^{2} \mu\left[\left(p_{b}-\delta+2 Q-s-3 w\right) \lambda\right.\right. \\
& \left.+4(Q-w)]-\gamma^{4}\left[\lambda^{2} Q+2 w+2 \lambda(Q+w)\right]\right]-\gamma^{2} \mu\left\{(1-\lambda)^{2} e_{0}^{2} \mu-4(Q-w) w\right. \\
& \left.\left.\left.\left.+\lambda\left[-4 Q^{2}+2 Q w+w\left(-p_{b}+\delta+s+2 w\right)\right]\right\}\right\}\right\}\right\}
\end{aligned}
$$$$
\begin{aligned}
& \hat{\eta}^{S}=\left\{\beta ^ { 2 } \left\{32 \gamma^{2} \lambda\left(p_{b}+c-\delta-e_{0} \gamma+e_{0} \gamma \lambda-s\right) \mu\left(p_{b}+c-\delta-e_{0} \gamma+e_{0} \gamma \lambda+\lambda Q-s-\lambda w\right)\right.\right. \\
& +\alpha^{3} \mu^{2}\left[5(c-w)^{2}+8 Q(4 Q+3 w-3 c)\right]+4 \alpha\left\{8 \gamma^{2} \lambda Q \mu\left[2 \delta+2(1-\lambda) e_{0} \gamma-\lambda Q \mu+2 s\right]\right. \\
& +8 p_{b}^{2} \mu^{2}+8\left[\delta+(1-\lambda) e_{0} \gamma\right]^{2} \mu^{2}+16\left[\delta+(1-\lambda) e_{0} \gamma\right](Q+s) \mu^{2}+8(2 Q+s) s \mu^{2} \\
& +c^{2}\left[\gamma^{4} \lambda^{2}+2 \gamma^{2}(4+5 \lambda) \mu+8 \mu^{2}\right]+8\left(\delta+e_{0} \gamma\right) \gamma^{2} \mu w+2\left(5 \delta+e_{0} \gamma-5 e_{0} \gamma \lambda+3 \lambda Q\right) \gamma^{2} \lambda \mu w \\
& +2(1-c)(4+5 \lambda) \gamma^{2} s \mu w-16\left[\delta+(1-\lambda) e_{0} \gamma\right] \mu^{2} w-16 s \mu^{2} w+\gamma^{4} \lambda^{2} w^{2}+2 \gamma^{2} \lambda^{2} \mu w^{2} \\
& -2 c\left\{\left(4+\lambda-5 \lambda^{2}\right) e_{0} \gamma^{3} \mu+(8-\lambda) \gamma^{2} \lambda Q \mu+8\left[(1-\lambda) e_{0} \gamma+Q+s\right] \mu^{2}+\left(p_{b}-\delta\right) \mu\left[\gamma^{2}(4+5 \lambda)+8 \mu\right]\right. \\
& \left.\left.+\gamma^{4} \lambda^{2} w+\left(4+5 \lambda+\lambda^{2}\right) \gamma^{2} \mu w-8 \mu^{2} w\right\}-2 p_{b} \mu\left[8 e_{0} \gamma(1-\lambda) \mu+8 \mu(\delta+Q+s-w)+\gamma^{2}(8 \lambda Q+4 w+5 \lambda w)\right]\right\} \\
& +4 \alpha^{2} \mu\left\{c^{2}\left[\gamma^{2}(2+3 \lambda)+6 \mu\right]+2 e_{0} \gamma(1-\lambda) \mu(8 Q+3 w)-2 \mu\left[(8 Q+3 w)\left(p_{b}-\delta-Q-s+w\right)+(Q-w) w\right]\right. \\
& -2 c\left\{3 e_{0} \gamma(1-\lambda) \mu+\mu\left(-3 p_{b}+3 \delta+10 Q+3 s+w\right)+\gamma^{2}[(4+5 \lambda) Q+(2+3 \lambda) w]\right\} \\
& \left.\left.\left.+\gamma^{2}\left[2 w(4 Q+w)+\lambda\left(8 Q^{2}+10 Q w+3 w^{2}\right)\right]\right\}\right\}\right\} \\
& /\left\{4 \alpha\left[-4 p_{b} \mu+4 \delta \mu+4(1-\lambda) e_{0} \gamma \mu+4 \alpha Q \mu+4 s \mu-c(4+\alpha) \mu+2 \gamma^{2} \lambda(w-c)+\alpha \mu w\right]^{2}\right\}
\end{aligned}
$$

Proof of Proposition 1 and 3. The derivation process of Proposition 1 is the same as that of Proposition 3. We take the derivation process of Proposition 3 as an example.

In Model SR, when the CSR input level is eliminated from the decision variables, the Hessian matrix of the manufacturer's profit function is given by:

$$
H\left(\pi_{m}^{S R}\right)=\left(\begin{array}{cc}
-\frac{2}{\alpha} & \frac{e_{0} \gamma \lambda}{\alpha} \\
\frac{e_{0} \gamma \lambda}{\alpha} & -e_{0}^{2} \mu
\end{array}\right)
$$

Obviously, $\pi_{m}^{S R}$ is a concave function of $p_{r}, \varepsilon$. Solve by reverse induction that $\varepsilon^{*}=$ $\frac{\gamma\left[\lambda\left(p_{b}+c-\delta-e_{0} \gamma+e_{0} \gamma \lambda-s\right)+\alpha(c-\lambda Q-w)\right]}{e_{0}\left(\lambda^{2} \gamma^{2}-2 \alpha \mu\right)}, \frac{\partial \varepsilon^{S R *}}{\partial v}=0 ;$

$$
\begin{gathered}
E^{*}=\frac{\gamma\left[\lambda\left(p_{b}+c-\delta-e_{0} \gamma+e_{0} \gamma \lambda-s\right)+\alpha(c-\lambda Q-w)\right]}{2\left(\lambda^{2} \gamma^{2}-2 \alpha \mu\right)} \\
* \frac{\left\{\gamma^{2} \lambda\left(p_{b}+c-\delta-e_{0} \gamma+e_{0} \gamma \lambda+\lambda Q+\beta \lambda v-s-\lambda w\right)+\alpha\left[c \gamma^{2}-2 \mu(Q+\beta v-w)-\gamma^{2}(\lambda Q+w)\right]\right\}}{2\left(\lambda^{2} \gamma^{2}-2 \alpha \mu\right)} \\
\gamma\left[c \gamma^{2} \lambda+2 p_{b} \mu+2 c \mu-2 \delta \mu-2 e_{0} \gamma(1-\lambda) \mu-2 \alpha Q \mu-2 s \mu-\gamma^{2} \lambda w\right]
\end{gathered}
$$$$
-\frac{\gamma\left[c \gamma^{2} \lambda+2 p_{b} \mu+2 c \mu-2 \delta \mu-2 e_{0} \gamma(1-\lambda) \mu-2 \alpha Q \mu-2 s \mu-\gamma^{2} \lambda w\right]}{2\left(\lambda^{2} \gamma^{2}-2 \alpha \mu\right)}
$$$$
* \frac{\left\{\gamma \lambda^{2}\left(-p_{b}-c+\delta+s\right)+\alpha\left[-c \gamma \lambda+2 e_{0}(1-\lambda) \mu+\gamma \lambda(\lambda Q+w)\right]\right\}}{2\left(\lambda^{2} \gamma^{2}-2 \alpha \mu\right)}
$$

$\frac{\partial E^{*}}{\partial v}=\frac{\gamma \beta\left[\lambda\left(p_{b}+c-\delta-e_{0} \gamma+e_{0} \gamma \lambda-s\right)+\alpha(c-\lambda Q-w)\right]}{2\left(\gamma^{2} \lambda^{2}-2 \alpha \mu\right)}>0$. Proof completed

Proof of Proposition 2 and 4. Since the derivation principle of Proposition 2 (1 3) is the same as that of Proposition 4 (1 4), taking Proposition 4 part 1 as an example, the proof process is as follows: $\varepsilon^{S N *}-\varepsilon^{S R *}=\frac{\alpha \gamma \lambda(w-c)}{2 e_{0}\left(2 \alpha \mu-\gamma^{2} \lambda^{2}\right)}>0, \varepsilon^{S N *}>\varepsilon^{S R *}$. Proof completed. 


\section{References}

1. Leard, B. Carbon Energy Taxation: Lessons from Europe. Energy J. 2011, 32, 241-245.

2. Fan, Y.Q.; Wang, W.J. Comparative study and enlightenment of European carbon tax policy practice. Economist 2012, 7, 96-104. [CrossRef]

3. Metcalf, G.E. Carbon Taxes in Theory and Practice. In Annual Review of Resource Economics; Rausser, G.C., Zilberman, D., Eds.; Annual Reviews: Santa Clara, CA, USA, 2021; Volume 13, pp. 245-265.

4. Chien, F.; Ananzeh, M.; Mirza, F.; Bakar, A.; Vu, H.M.; Ngo, T.Q. The effects of green growth, environmental-related tax, and eco-innovation towards carbon neutrality target in the US economy. J. Environ. Manag. 2021, 299, 9. [CrossRef] [PubMed]

5. Zhang, G.; Cheng, P.; Sun, H.; Shi, Y.; Zhang, G.; Kadiane, A. Carbon reduction decisions under progressive carbon tax regulations: A new dual-channel supply chain network equilibrium model. Sustain. Prod. Consum. 2021, 27, 1077-1092. [CrossRef]

6. Cheng, Y.; Sinha, A.; Ghosh, V.; Sengupta, T.; Luo, H. Carbon tax and energy innovation at crossroads of carbon neutrality: Designing a sustainable decarbonization policy. J. Environ. Manag. 2021, 294, 112957. [CrossRef] [PubMed]

7. Hammerle, M.; Best, R.; Crosby, P. Public Acceptance of Carbon Taxes in Australia Energy Economics; Eleviser: Amsterdam, The Netherlands, 2021; Volume 101.

8. Nong, D.; Simshauser, P.; Nguyen, D.B. Greenhouse gas emissions vs $\mathrm{CO}_{2}$ emissions: Comparative analysis of a global carbon tax. Appl. Energy 2021, 298, 117223. [CrossRef]

9. Galinato, G.I.; Yoder, J.K. An integrated tax-subsidy policy for carbon emission reduction. Resour. Energy Econ. 2010, 32, 310-326. [CrossRef]

10. Sun, Y.; Mao, X.; Yin, X.; Liu, G.; Zhang, J.; Zhao, Y. Optimizing carbon tax rates and revenue recycling schemes: Model development, and a case study for the Bohai Bay area, China. J. Clean. Prod. 2021, 296, 126519. [CrossRef]

11. Li, B.; Geng, Y.; Xia, X.; Qiao, D.; Wang, H. Comparatively Analyzing the Impact of Government Subsidy and Carbon Tax Policy on Authorized Remanufacturing. Int. J. Environ. Res. Public Health 2021, 18, 8293. [CrossRef]

12. Fogarty, J.J.; Sagerer, S. Exploration externalities and government subsidies: The return to government. Resour. Policy 2016, 47, 78-86. [CrossRef]

13. Xue, J.; Gong, R.; Zhao, L.; Ji, X.; Xu, Y. A Green Supply-Chain Decision Model for Energy-Saving Products That Accounts for Government Subsidies. Sustainability 2019, 11, 2209. [CrossRef]

14. Bian, J.; Zhang, G.; Zhou, G. Manufacturer vs. Consumer Subsidy with Green Technology Investment and Environmental Concern. Eur. J. Oper. Res. 2020, 287, 832-843. [CrossRef]

15. Satoshi, M.; Hiroshi, O. Effects of consumer subsidies for renewable energy on industry growth and social welfare: The case of solar photovoltaic systems in Japan. J. Jpn. Int. Econ. 2018, 48, 55-67.

16. Zhang, J.; Wang, Z.; Zhao, H. The Impact of Consumer Subsidy on Green Technology Innovations for Vehicles and Environmental Impact. Int. J. Environ. Res. Public Health 2020, 17, 7518. [CrossRef] [PubMed]

17. Cao, Y.; Xun, J.Y.; Li, Q.S. A Comparative Study of Green Efforts in Supply Chain Based on Different Government Subsidy Strategies. Oper. Res. Manag. Sci. 2020, 29, 108-118.

18. Sinayi, M.; Rasti-Barzoki, M. A game theoretic approach for pricing, greening, and social welfare policies in a supply chain with government intervention. J. Clean. Prod. 2018, 196, 1443-1458. [CrossRef]

19. Ren, J.; He, P.; Gong, B.G. Game Analysis between Government and Enterprises and the Strategy of Government Subsidies under Low-Carbon Economy. Oper. Res. Manag. Sci. 2016, 25, 258-265.

20. Graves, W. The Corporate Social Performance-Financial Performance Link. Strateg. Manag. J. 1997, 18, $303-319$.

21. Zhao, X.; Murrell, A.J. Revisiting the corporate social performance-financial performance link: A replication of Waddock and Graves. Strateg. Manag. J. 2016, 37, 2378-2388. [CrossRef]

22. Kim, Y.; Kim, T.; Nam, H.-J. Marketing Investments and Corporate Social Responsibility. Sustainability 2021, 13, 4849. [CrossRef]

23. Wagner-Tsukamoto, S.A. In search of ethics: From Carroll to integrative CSR economics. Soc. Responsib. J. 2019, 15, 469-491. [CrossRef]

24. Barnett, M.L.; Salomon, R.M. Does It Pay to be "Really" Good? Addressing the Shape of the Relationship between Social and Financial Performance. Strateg. Manag. J. 2012, 33, 16. [CrossRef]

25. Chen, C.-J.; Guo, R.-S.; Hsiao, Y.-C.; Chen, K.-L. How business strategy in non-financial firms moderates the curvilinear effects of corporate social responsibility and irresponsibility on corporate financial performance. J. Bus. Res. 2018, 92, 154-167. [CrossRef]

26. Jones, T.M. Instrumental Stakeholder Theory: A Synthesis of Ethics and Economics. Acad. Manag. Rev. 1995, 20, 34. [CrossRef]

27. Kao, E.H.; Yeh, C.-C.; Wang, L.-H.; Fung, H.-G. The relationship between CSR and performance: Evidence in China. Pac.-Basin Financ. J. 2018, 51, 155-170. [CrossRef]

28. Sun, W.; Ding, Y. Corporate social responsibility and cash flow volatility: The curvilinear moderation of marketing capability. J. Bus. Res. 2020, 116, 48-59. [CrossRef]

29. Zhang, Q.; Ahmad, S. Analysis of Corporate Social Responsibility Execution Effects on Purchase Intention with the Moderating Role of Customer Awareness. Sustainability 2021, 13, 4548. [CrossRef]

30. Raza, S.A. Supply chain coordination under a revenue-sharing contract with corporate social responsibility and partial demand information. Int. J. Prod. Econ. 2018, 205, 1-14. [CrossRef]

31. Panda, S.; Modak, N.; Cárdenas-Barrón, L.E. Coordinating a socially responsible closed-loop supply chain with product recycling Int. J. Prod. Econ. 2017, 188, 11-21. [CrossRef] 
32. Stranieri, S.; Orsi, L.; Banterle, A.; Ricci, E.C. Sustainable development and supply chain coordination: The impact of corporate social responsibility rules in the European Union food industry. Corp. Soc. Responsib. Environ. Manag. 2019, $26,481-491$. [CrossRef]

33. Liu, Y.; Li, J.; Quan, B.-T.; Yang, J.-B. Decision analysis and coordination of two-stage supply chain considering cost information asymmetry of corporate social responsibility. J. Clean. Prod. 2019, 228, 1073-1087. [CrossRef]

34. Wang, N.; Zhang, Y.L. Carbon emission reduction and coordination decisions of closed-loop supply chain under patent protection. Contr. Decis. 2020, 1-11. [CrossRef]

35. Lu, Y.; Liu, Q.; Li, J.H. The impact of government subsidies on the green innovation capability of new energy automobile companies. IOP Conf. Ser. Earth Environ. Sci. 2021, 680, 012113. [CrossRef]

36. Cheng, P.Y.; Ji, G.X.; Zhang, G.T.; Shi, Y.Y. A closed-loop supply chain network considering Consumer's low carbon preference and carbon tax under the cap-and-trade regulation. Sustain. Prod. Consum. 2022, 29, 614-635. [CrossRef]

37. Kong, J.; Yang, F.; Liu, T. Socially responsible supply chains with cost learning effects. RAIRO-Oper. Res. 2020, 54, 119-142. [CrossRef]

38. Liu, Y.; Ren, W.; Xu, Q.; Liu, Z. A coordination mechanism through cost sharing of corporate social responsibility and government subsidy in a two-echelon supply chain. J. Bus. Ind. Mark. 2021, 37, 29-46. [CrossRef]

39. Wang, Z.; Wang, M.; Liu, W. To introduce competition or not to introduce competition: An analysis of corporate social responsibility investment collaboration in a two-echelon supply chain. Transp. Res. Part E Logist. Transp. Rev. 2020, 133, 101812. [CrossRef]

40. Liu, W.; Wei, W.; Yan, X.; Wang, D. Supply Contract Design with Asymmetric Corporate Social Responsibility Cost Information in Service Supply Chain. Sustainability 2019, 11, 1408. [CrossRef]

41. Chen, Y.-S.; Chiu, S.-C.; Lin, S.; Wu, K.-H. Corporate social responsibility and income smoothing: Supply chain perspectives. J. Bus. Res. 2018, 97, 76-93. [CrossRef]

42. Mohsin, A.K.M.; Lei, H.; Hossain, S.F.A.; Tushar, H.; Alam Chowdhury, M.; Hossain, M.E. Operation and coordination mechanism of closed-loop supply chain considering corporate social responsibility behavior consciousness. Cogent Bus. Manag. 2020, 7, 1845937. [CrossRef]

43. Wang, C.; Zhang, Q.; Zhang, W. Corporate social responsibility, Green supply chain management and firm performance: The moderating role of big-data analytics capability. Res. Transp. Bus. Manag. 2020, 37, 100557. [CrossRef]

44. Wang, W.; Zhang, S.; Zhang, L.; Liu, Q. Government Subsidy Policies and Corporate Social Responsibility. IEEE Access 2020, 8 , 112814-112826. [CrossRef]

45. Li, S.; Li, M.; Zhou, N. Pricing and coordination in a dual-channel supply chain with a socially responsible manufacturer. PLoS ONE 2020, 15, e0236099. [CrossRef]

46. Long, X.; Ge, J.; Shu, T.; Liu, C. Production Decision and Coordination Mechanism of Socially Responsible Closed-Loop Supply Chain. Complexity 2020, 2020,1-10. [CrossRef]

47. Wang, Q.; Zhao, D.; He, L. Contracting emission reduction for supply chains considering market low-carbon preference. J. Clean. Prod. 2016, 120, 72-84. [CrossRef]

48. Zhou, W.Y.; Hu, W.; You, J.X.; Liu, G.F. A general model of remanufacturing for electromechanical products considering product-service system: A case study of BT industries. J. Manag. Case Stud. 2012, 5, 105-113.

49. Abbey, J.D.; Blackburn, J.D.; Guide, V.D.R. Optimal pricing for new and remanufactured products. J. Oper. Manag. 2015, 36, 130-146. [CrossRef]

50. Ferrer, G.; Swaminathan, J.M. Managing new and differentiated remanufactured products. Eur. J. Oper. Res. 2010, 203, 370-379. [CrossRef]

51. Savaskan, R.C.; Bhattacharya, S.; Van Wassenhove, L.N. Closed-Loop Supply Chain Models with Product Remanufacturing. Manag. Sci. 2004, 50, 239-252. [CrossRef]

52. Ferguson, M.E.; Toktay, L.B. The Effect of Competition on Recovery Strategies. Prod. Oper. Manag. 2006, 15, 351-368. [CrossRef]

53. Auger, P.; Devinney, T.M.; Louviere, J.J.; Burke, P.F. Do social product features have value to consumers? Int. J. Res. Mark. 2008, 25, 183-191. [CrossRef]

54. Li, H.; Wang, C.; Shang, M.; Ou, W.; Qin, X. Cooperative decision in a closed-loop supply chain considering carbon emission reduction and low-carbon promotion. Environ. Prog. Sustain. Energy 2018, 38, 143-153. [CrossRef]

55. Yi, Y.Q.; Xiang, Q. An Analysis of the New Energy Automotive Industry in China. China Soft Sci. 2009, 12, 60-63. Available online: https:/ / zgrk.cbpt.cnki.net/WKG/WebPublication/paperDigest.aspx?paperID=dc66b8d8-0c83-4622-9004-302d9fb54cb6 (accessed on 11 January 2022).

56. Guo, H.X. Report on Assessment of the New-Energy Vehicle Industry and Competition Environment. Sci. J. Econ. Manag. Res. 2020, 2, 8. Available online: http:/ / www.sjemr.org/download/SJEMR-2-8-25-30.pdf (accessed on 11 January 2022). 